\title{
An assessment of upper ocean salinity content from the ocean reanalyses inter- comparison project (ORA-IP)
}

Article

Accepted Version

Shi, L., Alves, O., Wedd, R., Balmaseda, M. A., Chang, Y., Chepurin, G., Ferry, N., Fujyii, Y., Gaillard, F., Good, S. A., Guinehut, S., Haines, K., Hernandez, F., Lee, T., Palmer, M., Peterson, K. A., Masuda, S., Storto, A., Toyoda, T., Valdivieso, M., Vernieres, G., Wang, X. and Yin, Y. (2017) An assessment of upper ocean salinity content from the ocean reanalyses inter-comparison project (ORA-IP). Climate Dynamics, 49 (3). pp. 1009-1029. ISSN 0930-7575 doi:

https://doi.org/10.1007/s00382-015-2868-7 Available at https://centaur.reading.ac.uk/52361/

It is advisable to refer to the publisher's version if you intend to cite from the work. See Guidance on citing.

To link to this article DOI: http://dx.doi.org/10.1007/s00382-015-2868-7

Publisher: Springer

All outputs in CentAUR are protected by Intellectual Property Rights law, including copyright law. Copyright and IPR is retained by the creators or other copyright holders. Terms and conditions for use of this material are defined in the End User Agreement. 


\section{www.reading.ac.uk/centaur}

\section{CentAUR}

Central Archive at the University of Reading

Reading's research outputs online 


\section{An Assessment of Upper Ocean Salinity Content from the 2 Ocean Reanalyses Inter-Comparison Project (ORA-IP)}

4 L. Shi ${ }^{1)}$, O. Alves $^{1)}$, R. Wedd ${ }^{1)}$, M. A. Balmaseda ${ }^{2)}$, Y. Chang ${ }^{3), 16)}$, G. Chepurin ${ }^{4)}$, N. Ferry ${ }^{10)}$, Y. Fujii ${ }^{5)}$, F.

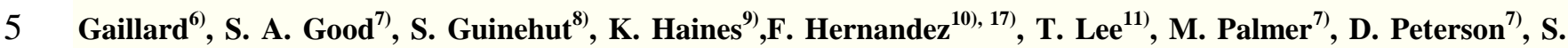

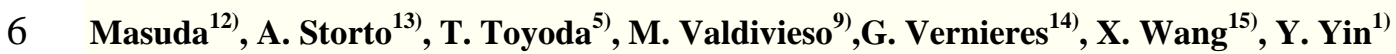

7 1) Research and Development Branch, Bureau of Meteorology, Australia

8 2) European Centre for Medium-Range Weather Forecasting (ECMWF)

9 3) Geophysical Fluid Dynamics Laboratory (GFDL), Princeton University, U. S. A.

10 4) University of Maryland, U.S.A.

11 5) Meteorological Research Institute (MRI), Japan Meteorological Agency

12 6) Laboratoire de Physique des Océans (LPO/IFREMER), France

13 7) Met Office Hadley Centre, United Kingdom

14 8) CLS / Space Oceanography Division, France

159 9) Reading University, United Kingdom

16 10) Mercator Océan, Ramonville Saint Agne, France

17 11) Jet Propulsion Laboratory (JPL), NASA, U. S. A.

18 12) Research and Development Center for Global Change, Japan Agency for Marine-Earth Science and Technology

19 13) Euro-Mediterranean Centre for Climate Change (CMCC), Italy

20 14) Global Ocean and Assimilation Office (GMAO), NASA, U. S. A.

21 15) Joint Institute for Regional Earth System Science and Engineering (JIFRESSE), UCLA

22 16) Department of Earth Science, Kongju National University, Korea

23 17) Institut de Recherche pour le Développement (IRD), Toulouse, France 


\section{Abstract}

Many institutions worldwide have developed ocean reanalyses systems (ORAs) utilizing a

variety of ocean models and assimilation techniques. However, the quality of salinity reanalyses arising from the various ORAs has not yet been comprehensively assessed. In this study, we assess the upper ocean salinity content (depth-averaged over 0-700m) from 14 ORAs and 3 objective ocean analysis systems (OOAs) as part of the Ocean Reanalyses Intercomparison Project (ORA-IP).

Our results show that the best agreement between estimates of salinity from different ORAs is obtained in the tropical Pacific, likely due to relatively abundant atmospheric and oceanic observations in this region. The largest disagreement in salinity reanalyses is in the Southern Ocean along the Antarctic Circumpolar Current (ACC) as a consequence of the sparseness of both atmospheric and oceanic observations in this region. The West Pacific Warm Pool (WPWP) is the largest region where the signal to noise ratio $(\mathbf{S N R})$ of reanalysed salinity anomalies is greater than

13 1. Therefore, the current salinity reanalyses in the tropical Pacific Ocean may be more reliable than 14 those in the Southern Ocean and regions along the western boundary currents. Moreover, we found that the assimilation of salinity in ocean regions with relatively strong ocean fronts is still a common problem as seen in most ORAs.

The impact of the Argo data on the salinity reanalyses is visible, especially within the upper $500 \mathrm{~m}$, where the interannual variability is large. The increasing trend in global-averaged salinity anomalies can only be found within the top 0-300m layer, but with quite large diversity among different ORAs. Beneath the 300m depth, the global-averaged salinity anomalies from most ORAs

21 switch their trends from a slightly growing trend before 2002 to a decreasing trend after 2002 . The rapid switch in the trend is most likely an artefact of the dramatic change in the observing system

23 due to the implementation of Argo. 


\section{Introduction}

Studies of the seasonal variability of salinity in the tropical oceans have revealed that the

salinity changes, in particular in the upper ocean, are strongly impacted by river discharges, surface

4 freshwater flux (i.e., evaporation and precipitation; referred as E-P hereafter), and advection etc.

5 (Cronin and McPhaden, 1998; Johnson et al. 2002; Foltz et al. 2004). On decadal timescales, changes in global ocean salinity can be mainly attributed to changes in the global hydrological cycle, in particular the E-P pattern changes, (Curry et al. 2003; Durack and Wijffels 2010; Durack et al. 2012) that is possibly linked to global warming (Held and Soden 2006). In the high latitude Atlantic, the long-term salinity changes are impacted by the wind-driven export of ice, river discharge from the Arctic and advection by the currents (Vinje 2001; Belkin 2004).

A number of papers have indicated that salinity has a great impact on the global ocean dynamical and thermal circulation through density and dynamical height variations (Cooper 1988; Rahmstorf, 1996; Murtugudde and Busalacchi 1998; Vialard et al. 2002; Fedorov et al. 2004; Zhang and Vallis 2006; Huang et al. 2008). For instance, "Great Salinity Anomalies (GSAs)" events, that have occurred during the 1970s, 1980s and 1990s in the North Atlantic Ocean (Dickson et al. 1988; Belkin et al. 1998; Belkin 2004), may play an important role in the variations of the thermohaline circulation, deep western boundary current, northern recirculation gyre, and Gulf Stream, etc. (Wadley and Bigg 2006; Zhang and Vallis 2006). The close link between salinity variability in the western Pacific and subsequent ENSO events has also been revealed from both observational investigations and dynamical model simulations (Maes et al., 2005, 2006; O'Kane et al. 2014; Zhu et al. 2014). Furthermore, some studies have pointed out that the assimilation of observed salinity can provide more accurate initial ocean states for dynamical models since the imbalance between temperature and salinity is reduced, thereby resulting in better ENSO prediction skills (BallabreraPoy et al., 2002; Vialard et al., 2002; Yang et al. 2010; Hackert et al. 2011; Zhao et al. 2013, 2014; Zhu et al. 2014). 
Most research and operational centres around the world have established their own ocean

2 reanalysis systems (ORAs) for the purpose of building up historical ocean datasets and providing

3 initial conditions for a range of forecast systems. In the early stages, the products from ORAs

4 (Balmaseda et al 2009) mainly focused on the assimilation of observed temperature, while salinity

5 was not adjusted at all or was constructed from the local climatological temperature-salinity (T-S)

6 relationship, mainly due to the paucity of salinity observations (Behringer and Xue 2004). Since the

7 international Argo Project (http://argo.jcommops.org), which collects real-time temperature and

8 salinity profiles in upper 2000 metres of the ocean, started to provide comprehensive global ocean

9 coverage from around 2006 onwards, most state-of-the-art ORAs assimilate both observed sea

10 temperature and salinity profiles by using a variety of assimilation methods (Table 1).

11 To date, there is no intercomparison of the performance of salinity reanalyses from the latest

12 vintage of ORAs from around the world. However, there have been several assessments of salinity

13 analyses from some individual ORAs (Hernandez et al. 2009; Xue et al. 2011; Chang et al. 2012;

14 Fujii et al. 2012). The Ocean Reanalyses Intercomparison Project (ORA-IP) was proposed by the

15 participants of the joint GODAE (Global Ocean Data Assimilation Experiment)

16 OceanView/CLIVAR GSOP (Global Synthesis and Observation Panel) workshop in Santa Cruz in

17 June 2011 for the purpose of real time ocean monitoring and operational seasonal forecast systems

18 improvement (Balmaseda el al. 2015). The work presented here is a contribution to the ORA-IP

19 project. Its primary objective is to quantify the ensemble spread and signal to noise ratio in the

20 estimation of salinity from an ensemble of existing global ocean reanalyses. This is the first step to

21 evaluate the maturity level of existing global products. By identifying current deficiencies, it is

22 expected that ORA-IP can help with the future development of ocean data assimilation and

23 observing systems. The work presented here is only an initial and broad quantification of the signal

24 to noise ratio, and it will not deal with the representation of process or specific modes of variability.

25 We expect that further studies can follow once the ORA-IP data is made publicly available. 
This paper is organized into six sections. Section 2 presents a brief description of the ORAs

2 included in this study. The mean state of the reanalysed salinity for the period from 1993 to $2010^{\Delta}$

3 is assessed in section 3. In section 4, the variability of the salinity reanalyses, such as standard

4 deviation, signal-to-noise ratio and temporal correlation is evaluated. In this section, the temporal

5 correlation between local salinity anomalies and temperature anomalies and the impact of Argo data

6 on the salinity reanalyses is also discussed. Furthermore, we will also examine the trend in global

7 average salinity anomalies over depth levels above 1500 meters in section 5 . The final section

8 contains a discussion and conclusions.

\section{Reanalyses Systems}

Critical information (e.g., referred names and associated institutions; ocean model resolutions; atmospheric forcing; main assimilation methods, assimilated observations and relaxation to climatology) of the products assessed in this study is summarized in Table 1 . The total of 17 estimates can be roughly classified into two groups: the first one consists of fourteen ORAs (the first fourteen in Table 1) which all assimilated various ocean observations into a variety of dynamical ocean model systems (coupled or uncoupled); the second group, in contrast, consists of ARMOR3D, ISAS13 and EN3v2a in which their salinity reanalyses are obtained from ocean observations through a statistical method with no dynamical ocean model. Thus, the three products

19 in the second group are referred to as Objective Ocean Analyses (OOAs) hereafter.

The main assimilation techniques used by the fourteen ORAs can be simply summarised as:

21 Optimal Interpolation (OI; e.g., SODA and ORAS3), Ensemble OI (EnOI; e.g., GMAO), 3dimension variational method (3DVAR; e.g., GloSea5, ORAS4, CGLORS, MOVE-C, MOVE-G2 and G2V3), 4-dimension variational method (4DVAR; e.g., ECCOV4 and K7ODA^), Kalman

\footnotetext{
${ }^{\Delta}$ Exception is the ISAS13, which is only available from 2002-2010 in this study. Hereafter, all the calculation of ISAS13, thus, is based on the period from 2002-2010.

C Changes in water volume in conjunction with a free surface model used by K7ODA are ignored in this study.
} 
1 Filter method (KF; e.g., G2V3), and Ensemble Kalman Filter (EnKF; e.g., ECDA, PEODAS*,

2 PECDAS). The atmospheric surface forcing for most of the 14 ORAs are obtained from

3 atmospheric reanalyses through a variety of methodologies (e.g., corrected fluxes, different bulk

4 formulations) except that three ORAs (e.g., PECDAS, ECDA and MOVE-C) are provided by the

5 atmospheric component of the corresponding coupled model.

6 In addition to observed Temperature/Salinity (T/S) profiles, various other ocean observations, such as altimeter-derived Seal Level Anomalies (SLA); Sea Surface Height (SSH) from tide gauges; Sea Surface Temperature (SST) and satellite derived Sea-Ice Concentration (SIC), are also assimilated by some of the ORAs in Table 1. In order to prevent the model from drifting, most ORAs relax their 3 dimensional (3D) T/S or Sea Surface Salinity (SSS) to climatology with

11 differing relaxation time intervals (Table 1). Although a few studies have suggested the potential impact of SSS on SST variability in the tropical Pacific (Ballabrera-Poy et al. 2002; Wang and

13 Chao 2004; Hackert et al. 2011), the performance of SSS reanalyses will not be assessed in this paper because SSS is defined differently in each ORA (e.g., different layer depths). In this study, we will mainly focus on the depth-averaged salinity over the upper 0-700m ocean layer ${ }^{\#}(\mathbf{S 7 0 0})$ since the largest salinity changes are usually observed in the upper 500 meters (Curry et al. 2003; Boyer et al. 2005; Durack and Wijffels 2010). For this study, all the monthly salinity fields from the ORA-IP participants have been interpolated to a standard $1^{\circ} \times 1^{\circ}$ latitude-longitude grid.

The biggest problem in the assessment of salinity reanalyses from various ORAs is the absence of "reality" or proper standard due to the paucity of salinity observations, especially prior to Argo.

21 We will focus on the ensemble spread (SPD; refer to the Eq. (A2-3) for details; noted as ensemble standard deviation in Balmaseda et al. 2015) of the variable ' $X$ ' from 14 ORAs about their corresponding ensemble mean (EMORA; refer to the Eq. (A1) for details). This can be used to measure the diversity / agreement of the salinity between different ORAs. Following previous

\footnotetext{
* In a strict sense, PEODAS is an approximate form of an ensemble Kalman filter system (Yin et al. 2011).

\# The S700 values in the ocean coast regions, where the deepest depth is less than 700 meters, are defined as missing value.
} 
1 studies (Lee et al. 2009; Zhu et al. 2012), we also consider the standard deviation (STD; refer to

$2 S T D_{E M O R A}^{A}$ in the Eq. (A8)) of EMORA variability as the 'signal' (or certainty) part of the variability

3 of salinity reanalyses from the 14 ORAs. Thus, the corresponding $S P D$ (refer to $S P D_{\text {EMORA }}^{X}$ in the Eq.

4 (A2-3)) can be considered a quantitive measurement of the 'noise' (or uncertainty), which is caused

5 by different assimilation methods, atmospheric forcing and ocean model dynamics etc., from the 14

6 ORAs. Therefore, the 'uncertainty' mentioned hereafter in this study cannot simply be considered

7 as the true 'error' between the reanalyses and the observations. For instance, it is possible that all

8 the products have similar systematic error, which will not be captured by this ensemble method. As

9 discussed by Balmaseda et al (2015), the ensemble method also assumes that all the estimates have

10 similar quality, which may not always be applicable.

11 The ensemble mean of the 3 OOAs (EMOO; refer to $\overline{X_{E M O O}}$ or $\overline{X_{E M O O}^{A}}$ in the Eq. (A1)) will be

12 compared with EMORA in this paper. This comparison should illustrate the main differences

13 between statistical and dynamical data assimilation estimates, assuming the bulk of in-situ salinity

14 observations are likely to be similar in ORAs and OOAs. The salinity from OOAs is likely to be

15 close to climatology prior to Argo due to the lack of observations. Even during the Argo period, we

16 note that the salinity reanalyses from the 3 OOAs or the corresponding EMOO cannot simply be considered as the proxy of 'reality' due to inhomogeneous temporal and spatial distribution of Argo. In contrast, the salinity in ORAs is affected not only by the salinity observations, but also by model

19 dynamics and mixing, surface fluxes, and imposed multivariate relations (for instance, observations 20 of temperature and sea level can affect the salinity). This variety of information sources in ORAs 21 can contribute to the coherence of the signal, but also to the ensemble spread, since there is large uncertainty in ocean models, surface fluxes and multivariate relationships.

\section{3. Mean State}


Compared to EMOO (Fig. 1b), the AMS700 of EMORA (Fig.1a) is relatively saltier ( $\geq 0.1$ psu)

2 in the Southern Ocean along the ACC and in the Kuroshio. A striking dipole appears along the Gulf

3 Stream/Labrador Current system, where the AMS700 of EMORA is fresher/saltier than that of

4 EMOO by more than $0.1 \mathrm{psu}$, respectively. This difference is consistent with the well-known

5 systematic error in ocean models (incorrect strength and path of the Gulf Stream and Labrador

6 Current). It is likely that in this area EMOO are relatively well constrained by the existing salinity

7 observations. The large differences along the northern edge of the ACC are also likely to have a

8 dynamical origin, but in this case EMOO may have significant uncertainty, due the paucity of in-

9 situ observations. There are also large scale differences in the meridional distribution of salinity,

10 which varies across basins. Thus, in the Atlantic, the AMS700 of EMORA shows a saltier

11 equatorial band and fresher sub-tropical gyres than that of EMOO, while the opposite pattern occurs

12 in the Pacific. Differences associated with the Equatorial Pacific current system are also visible.

13 Generally, the regions of relatively large $S P D_{E M O R A}^{A M}$ of AMS700 ( $S P D_{E M O R A}^{A M} \geqslant 0.1 \mathrm{psu}$ ) shown in

14 Fig.1c, such as in the Southern Ocean along the ACC, the Kuroshio and the Gulf Stream,

15 correspond with the regions of relatively large differences of AMS700 shown in Fig.1a. This

16 indicates that the existing observations are not able to constrain the large diversity among different

17 ORAs in these areas, at least with the current assimilation systems. The spatial pattern of $S P D_{E M O R A}^{A M}$ in

18 the Atlantic resembles the footprint of the wind driven circulation.

19 In order to demonstrate the individual performance of each ORA, the zonal distributions of the

20 differences of AMS700 between each product and EMOO are shown in Fig. 2a (meridionally

21 averaged over $\left.30^{\circ} \mathrm{N}-60^{\circ} \mathrm{N}\right), 2 \mathrm{~b}\left(15^{\circ} \mathrm{S}-15^{\circ} \mathrm{N}\right)$ and $2 \mathrm{c}\left(60^{\circ} \mathrm{S}-30^{\circ} \mathrm{S}\right)$, respectively. The definition of the

22 shaded band in Fig. 2, which represents the uncertainty range (i.e., $U C R_{E M O R A}^{A M}$ ) of AMS700 differences

23 from the 14 ORAs about their EMORA, is detailed in the Eq. (A4). Thus, the ORAs outside the

24 shaded band can be considered as outliers. 
The AMS700 differences between OOAs and EMOO are generally smaller than that between

2 each ORA and EMOO in most parts of oceans except for the relatively large AMS700 differences

3 for ISAS13 shown in the northern Atlantic and the tropical Pacific. This feature can probably be

4 attributed to the calculation period for the ISAS13 (i.e., 2002-2010) which is shorter than that for

5 other products (i.e., 1993-2010).

6 In the northern band (averaged over $30^{\circ} \mathrm{N}-60^{\circ} \mathrm{N}$; Fig.2a), the $U C R$ of AMS700 differences

7 gradually increases eastward in the northern Pacific Ocean, but gradually decreases eastwards in the

8 North Atlantic Ocean. Compared to the tropical Indian Ocean and Atlantic Ocean, the obviously

9 smaller UCR of AMS700 differences in the tropical Pacific Ocean can be attributed to the relative

10 abundance of observations there. The UCR of AMS700 differences in the southern band (averaged

11 over $60^{\circ} \mathrm{S}-30^{\circ} \mathrm{S}$; Fig. 2c) is relatively large in the Indian Ocean sector and Pacific Ocean sector,

12 presumably due to sparsity of observations. However, it is relatively lower in the Atlantic sector of

13 the Southern Ocean. K7ODA is seemingly an outlier. This is mainly from the fact that its S700 is

14 calculated under the assumption of constant water volume of the first ocean layer despite a free

15 surface ocean model applied in K7ODA.

16 The seasonal cycle (i.e., January-December monthly climatology) of S700 for a moored buoy

17 located at $8^{\circ} \mathrm{N}, 156^{\circ} \mathrm{E}$ (referred as T8N156E) is selected to compare with all products in Table 1 at

18 the same location (by linear interpolation) and same period (1999-2010). The differences in the

19 observed seasonal cycle for each ORA are shown in Fig. 3. This buoy has observations for the

20 longest available period (from Feburary1999) and covers the most depth layers (from $1.5 \mathrm{~m}$ to $750 \mathrm{~m}$

21 depth) among all buoy sites of the TAO/TRITON array (available at

22 http://www.pmel.noaa.gov/tao/proj_over/triton.html). Generally, the average $U C R_{E M O R A}^{S C}(\approx 0.02 \mathrm{psu}$;

23 shaded band in Fig. 3; refer to the Eq. (A4)) along the seasonal cycle of S700 differences between

24 all ORAs and the T8N156E buoy are significantly smaller than that $(\approx 0.1 p s u)$ in other regions

25 (Fig. 2). The bias of EMOO is comparable to that of EMORA. This is not surprising, given the 
1 availability of observations at this specific location. A few individual ORAs show differences

2 comparable with EMOO or EMORA. However, the spread among the ORAs is much larger than

3 the spread among OOAs. This is indicative that errors in ocean models, surface forcing and data

4 assimilation methods are still an issue for the precise estimation of salinity. For instance, over-

5 estimation of precipitation in the tropical band by most atmospheric reanalyses has been reported by

6 several studies (Janowiak et al. 2010; Kim and Alexander 2013).

\section{4. Temporal Variability}

\subsection{Standard Deviation}

The first assessment of salinity variability is the standard deviation (STD; refer to the Eq. (A7-

11 8)), which is an important indicator of the amplitude of S700 anomalies ${ }^{+}$(seasonal cycle removed) from all products for the period 1993-2010 (Fig.4). In the northern band $\left(30^{\circ} \mathrm{N}-60^{\circ} \mathrm{N}\right.$ average; Fig. 4a), the $S T D_{n}^{A}$ (refer to the Eq. (A7)) of S700 anomalies from most ORAs in the central north Pacific is generally smaller than that in the north-western and north-eastern Pacific, but the $U C R_{E M O R A}^{S T D}$ (refer to the Eq. (A4); shaded band in Fig. 4) is very similar over the whole northern Pacific. In the North Atlantic Ocean, the STD of S700 anomalies from all products, as well as the $U C R_{E M O R A}^{S T D}$, significantly decreases from west (i.e., the Gulf Stream) to east. The $S T D_{\text {EMORA }}^{A}$ (refer to the Eq. (A8)) of S700 anomalies from EMORA agrees well with that from EMOO (i.e., $S T D_{E M O O}^{A}$; refer to the Eq. (A8)) except for the Gulf Stream.

In the tropical oceans $\left(15^{\circ} \mathrm{S}-15^{\circ} \mathrm{N}\right.$ average; Fig. $\left.4 \mathrm{~b}\right)$, the largest $U C R_{E M O R A}^{S T D}$ occurs in the Atlantic

21 Ocean, especially in the eastern part of the basin. In the Indian Ocean, the $U C R_{E M O R A}^{S T D}$ and amplitude of S700 anomalies is largest in the central-eastern Indian Ocean (around $90^{\circ} \mathrm{E}$ ). In the Pacific, both

23 the $U C R_{E M O R A}^{S T D}$ and the amplitude of the S700 anomalies is largest in the western edge of the WPWP

\footnotetext{
${ }^{+}$Hereafter, the 'anomalies' in this study are relative to the corresponding January-December monthly climatology (i.e., seasonal cycle).
} 
1 region (around $165^{\circ} \mathrm{E}$ ), and then, decreases both eastwards and westwards. In contrast, in the

2 Atlantic Ocean the largest $S T D_{n}^{A}$ from most ORAs, as well as the $U C R_{E M O R A}^{S T D}$, is seen in both the east

3 and west (e.g., the Gulf of Guinea). The $S T D_{\text {ЕмовА }}^{A}$ of S700 anomalies from EMORA is consistently

4 larger than the $S T D_{\text {Емоо }}^{A}$ from EMOO, especially in the central tropical Indian Ocean, central-western

5 tropical Pacific and western tropical Atlantic Ocean. Most individual ORAs (with the exceptions of

6 ECCOV4 and K7ODA) exhibit higher variability than that of individual OOAs, which highlights

7 the contribution of models and surface forcing to the estimation of salinity variability. The

8 differences in variability of S700 anomalies among the 3 OOAs are not small, even in the tropical

9 Pacific Ocean where there is a relative abundance of observations. ARMOR3D seems to be the

10 outlier, showing very small STD of S700 anomalies.

11 The $S T D_{n}^{A}$ of S700 anomalies from most ORAs, as well as the $U C R_{E M O R A}^{S T D}$, in the Southern Ocean

12 along the ACC region (Fig. 4c) is generally larger than that in the tropical oceans and the northern

13 band. This relatively large $U C R_{E M O R A}^{S T D}$ is likely caused by the lack of observation that results in the

$14 S T D$ of S700 anomalies becoming more dependent on the ocean model, assimilation method and

15 atmospheric forcing etc. The $S T D_{E M O R A}^{A}$ of S700 anomalies from EMORA is smaller than that of most

16 individual ORAs, and comparable to the $S T D_{\text {Емоо }}^{A}$ from EMOO, suggesting a lack of coherence in the

17 variability of individual ORAs. Exceptions are the convergence zone (around $45^{\circ} \mathrm{W}$ ) of the Brazil

18 Current and the South Atlantic Current; the convergence zone (around $15^{\circ} \mathrm{E}$ ) of the Benguela

19 Current and the Agulhas Current. In these dynamically active regions the ocean model is likely to

20 be playing a significant role.

21 It is worth noting that most ORAs show relatively large STD of S700 anomalies than the 3

22 OOAs over most parts of oceans. Although the amplitude of salinity variability may be

23 overestimated by the model-based ORAs, it is also possible that the 3 OOAs underestimate the

24 variability because in regions of sparse observations they will be closer to climatology. The 
$1 U C R_{E M O R A}^{S T D}$ (up to $0.05 \mathrm{psu}$ ) of the $S T D_{n}^{A}$ of S700 anomalies in Fig. 4 is smaller than that of

2 corresponding AMS700 differences (around 0.1 psu) shown in Fig. 2, except for the tropical Pacific

3 Ocean and the Atlantic sector of the Southern Ocean. Additionally, we note that the $S T D_{\text {EMORA }}^{A}$ of

4 EMORA is smaller than that of individual ORA in most cases, except for the tropical Indian-Pacific

5 Ocean. This feature implies that the variability of S700 anomalies from individual ORA is quite

6 diverse, and different from EMORA in most cases. The phase agreement of S700 variability

7 between all individual ORAs and EMOO will be assessed further in the next sub-section 4.2.

8 There is no specific ORA that is an overall outlier in Figs 2 and 4. It suggests that no specific

9 ORA is the best or worst one among all 14 ORAs in this study. However, in specific regions there

10 are specific outliers, for example, the K7ODA in the North Atlantic Ocean and the Southern Ocean;

11 the GloSea5 and G2V3 in the tropical Pacific Ocean; the PEODAS and PECDAS in the western

12 tropical Atlantic Ocean.

\subsection{Signal-to-Noise Ratio}

The $S P D$ of S700 anomalies from each ORA about the corresponding EMORA (refer to $S P D_{\text {EMORA }}^{A}$ in the Eq. (A3)) is shown in Fig.5a. The geographical distribution of the largest $S P D_{\text {EMORA }}^{A}$ of S700 anomalies ( $\geqslant 0.1 \mathrm{psu})$ is associated with the largest $S P D_{\text {EMORA }}^{A M}$ of AMS700 (see Fig. 1c), particularly in the western boundary currents, such as the Kuroshio, Gulf Stream and Brazil Current.

19 Other areas of relatively large $S P D_{E M O R A}^{A}$ of $\mathrm{S} 700$ anomalies ( $\geqslant 0.06 \mathrm{psu}$ ) can be seen in the sub-

20 tropical eastern Indian Ocean and central Pacific Ocean. As was discussed in Balmaseda et al.

21 (2015), the areas of the relatively large uncertainty in salinity reanalyses tends to occur in regions associated with both strong temperature and salinity fronts. Of course, the effects of the ocean models and assimilation techniques on the uncertainty cannot be discarded. 
As mentioned above, the $S T D_{\text {ЕMоRA }}^{A}$ of S700 anomalies from EMORA (Fig. 5b), can be

2 considered as a quantitive estimate of the signal. The regions with the largest signal mainly occur in

3 the WPWP region, central Indian Ocean, Gulf of Alaska along the Alaska Current and a narrow

4 band in the Southern Ocean (around $40^{\circ} \mathrm{S}, 20^{\circ} \mathrm{W}-70^{\circ} \mathrm{E}$ ). It is also high in areas of strong variability

5 such as the western boundary currents in Atlantic Ocean. Strong variability occurs in the WPWP

6 due to strong rainfall and current variability.

Following the approach used by Lee et al. (2009) and Zhu et al. (2012); the ratio of the $S T D_{\text {EMORA }}^{A}$

8 (Fig.5b) to the $S P D_{E M O R A}^{A}$ (Fig.5a) of S700 anomalies can be considered as the so-called signal to

9 noise ratio $(\boldsymbol{S N R})$ that gives a good quantitative estimate of the reliability of S700 variability among

10 the different ORAs. As shown in Fig. 5c, the regions where the SNR is greater than 1 mainly appear

11 in the WPWP region, central tropical Indian Ocean, the Gulf of Alaska and other small regions of

12 the mid-latitude oceans. The relatively large $S N R$ over the WPWP, which is also an area of large

13 interannual variability, is likely related to the constraint provided by the salinity observations from

14 the TAO/TRITON moorings. Overall, the SNR is less than 1 over most parts of oceans, indicating

15 that there is relatively large $S P D_{E M O R A}^{A}$, and therefore, disagreement in the estimates of S700

16 anomalies among different ORAs.

\subsection{Correlation}

Fig.6a illustrates how well the S700 variability in the two ensemble means agree with each other. Correlations are relatively high $(\geq 0.75)$ in the central and western equatorial Pacific, western

21 sub-tropical Pacific along the Kuroshio and north-eastern mid-latitude Pacific. They are also high in the eastern equatorial Indian Ocean, and throughout parts of the sub-tropical and mid-latitude

23 oceans. Correlations are relatively low $(\leq 0.5)$ around the northern edge of the ACC, western Indian 24 Ocean and parts of the sub-tropical Atlantic, particularly downstream of the Mediterranean outflow. 
The S700 variability of each ORA can be correlated with that of EMOO. And then, the

$2 S P D_{\text {EMORA }}^{\text {COR }}$ of the correlations from 14 ORAs about their corresponding ensemble average of all 14

3 correlations (refer to the Eq. (A2) for details) provide an indication of the disagreement in the

4 estimate of variability between the different systems (Fig. 6b). There is some correspondence

5 between areas with large $S P D_{\text {ЕMORA }}^{\text {COR }}$ and low correlation in Fig.6a, such as the northern edge of the

6 ACC in the Pacific sector and the northern part of the tropical Atlantic. Equally, the high correlation

7 in the Tropical Pacific, Eastern Indian Ocean, North East Pacific and North East Atlantic, where the

8 spread is low, is indicative of consistency between the different estimates. The Southern Ocean is

9 an exception, showing relatively large values of the correlation and the $S P D_{\text {EMORA }}^{C O R}$.

10 The WPWP region and central tropical Indian Ocean, the regions with the smallest $S P D_{\text {EMORA }}^{C O R}$

11 (best agreement among all ORAs, Fig. 6b), also have the highest $S N R$ values (Fig. 5c). It is worth

12 noting that these regions are also the places where the largest precipitation variability occurs (Storto

13 et al. 2015).

14 Fig. 7 shows the zonal distributions of the correlation of S700 anomalies between each ORA

15 and EMOO for the period 1993-2010. EMORA, unsurprisingly, obtains the highest correlation

16 among all ORAs over most parts of oceans due to averaging out the impacts of different ocean

17 models, forcing fields and assimilation techniques etc. Generally, the areas of relatively high

18 correlation, associated with relatively small $U C R_{E M O R A}^{C O R}$ (refer to the Eq. (4)), are in the eastern tropical

19 Indian Ocean, central-western tropical Pacific and north-east Pacific. In contrast, the areas of

20 relatively low correlations, associated with relatively large $U C R_{E M O R A}^{C O R}$, are in the Southern Ocean and

21 the tropical and north-west Atlantic Ocean.

\subsection{Local T-S Correlation}

The close relationship between seawater temperature and salinity (T-S) is too complicated to be precisely described and measured in one simple way. However, in this study, we utilize the 
1 correlation between the local S700 anomaly and the corresponding depth-averaged temperature

2 (over upper 0-700m ocean layer, referred as T700) anomaly to investigate how the co-variability

3 between T700 and S700 anomalies represented by the ORAs compares with that of EMOO. Figs. 8a

4 and $8 \mathrm{~b}$ show the temporal correlation between the T700 anomaly and S700 anomaly from

5 EMORA (Fig. 8a) and EMOO (Fig.8b) for the period 1993-2010. The distribution of T700-S700

6 correlations from EMORA is quite similar to those of EMOO, showing coherent large scale patterns.

7 For instance, relatively high positive correlation in most parts of Atlantic Ocean, equatorial Pacific,

8 north-eastern and southern sub-tropical Pacific, southern sub-tropical Indian Ocean; whereas,

9 negative correlations mainly occur in the eastern equatorial Indian Ocean, the north-eastern

10 boundary of the Pacific (i.e., off the east coast of Mexico and the Gulf of Alaska), and in particular

11 the Southern Ocean. However, EMORA (Fig. 8a) produces more extreme positive and negative

12 correlation than EMOO (Fig. 8b). Yet, the region of negative correlation for EMORA is smaller

13 than that of EMOO, in particular the narrower negative correlation belt in the Southern Ocean in

14 Fig.8b. It seems that most ORAs exhibit a stronger relationship between the local salinity content

15 and heat content compared to EMOO, in particular in the north-west Indian Ocean, the equatorial

16 Atlantic Ocean, and the northern edge of the ACC in the Indian-Pacific Ocean sector. In this area,

17 where there are few temperature and salinity observations, the associated relationship between local

18 salinity and temperature in the ORAs may come from the ocean-model information, which is absent

19 in the OOAs.

20 There is no unique explanation for the large scale patterns of correlation between T700 and

21 S700. It is possible that changes associated with local vertical displacement of the water column

22 related with, say, variations in Ekman pumping, would result in positive/negative correlation of

23 T700-S700 wherever the temperature and salinity vertical stratification (above and below 700m)

24 has the same/opposite sign. But changes associated with horizontal displacement of water masses,

25 or changes in the water mass properties cannot be discarded either. 
Fig.8c shows the $S P D_{\text {EMORA }}^{\text {COR }}$ (refer to the Eq. (A2) for details) of the T700-S700 correlation from

2 all ORAs about the corresponding ensemble average correlation (refer to $\overline{X_{E M O R A}}$ in the Eq. (A1))

3 for the period 1993-2010. The largest $S P D_{E M O R A}^{C O R}$ of the T700-S700 correlation among the ORAs

4 occurs in the Southern Ocean. This disagreement can be attributed to the lack of observations in this

5 region, and to the different T700-S700 correlation among ocean models.

6 The zonal distributions of T700-S700 correlation from each ORA are shown in Fig.9. The

7 correlations from most ORAs agree quite well with that of the OOAs in some parts of ocean, for

8 instance, in the mid-latitude North Pacific and the eastern tropical Pacific. In some other parts of

9 oceans, however, the correlation of most ORAs is higher than that of OOAs, such as in the central-

10 western tropical Pacific, central tropical Indian Ocean, the Southern Ocean in both Indian Ocean

11 sector and east Pacific sector, and in particular in the tropical Atlantic Ocean where the correlation

12 of OOAs is around 0.4 but the correlations of most ORAs are generally more than 0.6 (Fig.9b). In

13 the tropical Indonesian Sea/eastern Indian Ocean area $\left(90^{\circ} \mathrm{E}-130^{\circ} \mathrm{E}\right)$, most $\mathrm{ORAs}$ show negative

14 local T700-S700 correlations (up to -0.6; Fig. 9b). We suspect this may be attributed to the

15 Indonesian Throughflow (ITF) transporting relatively warmer and fresher sea water from the Pacific

16 Ocean into the Indian Ocean (Vranes et al. 2002; Sprintall et al. 2009).

\subsection{Impacts of Argo}

Figure 10 shows the depth/time evolution (1993-2010) of the centred pattern correlation coefficients $^{\wedge}$ (i.e., $\boldsymbol{C P C O R}$; refer to the Eq. (A9); Santer et al. 1993; Storch and Navarra 1999) of

21 salinity anomalies between EMORA and EMOO, averaged over $0-360^{\circ} \mathrm{E} ; 30^{\circ} \mathrm{N}-60^{\circ} \mathrm{N}$ (Fig.10a); $15^{\circ} \mathrm{S}-15^{\circ} \mathrm{N}$ (Fig.10b); $60^{\circ} \mathrm{S}-30^{\circ} \mathrm{S}$ (Fig.10c), respectively. The vertical distribution of $C P C O R$ in

23 both the mid-latitude northern oceans (Fig.10a) and the tropical oceans (Fig.10b) generally decrease

24 downwards from 100-1500m depth. Relatively high correlation $(\geq 0.5)$ is obtained over the upper

\footnotetext{
A 7-month running mean has been applied on the computed correlation coefficients to remove the intra-seasonal variability.
} 
$1300-400 \mathrm{~m}$ depth before 2001, and then, increases up to more than 0.9 and extended to 500-600m

2 depth after 2002. This increase corresponds quite well with the beginning of the Argo project. The

3 relatively higher $C P C O R$ within the upper 500m ocean layer in both mid-latitude and tropical

4 oceans after 2002 indicates higher consistency in the estimated pattern of salinity anomalies by both

5 EMORA and EMOO due to Argo. The CPCOR decreases downwards with the depth increasing,

6 and is likely attributed to a lack of coherence between the anomaly patterns from EMORA and

$7 \quad$ EMOO.

8 In contrast, the vertical distribution of CPCOR in the Southern Ocean band (Fig. 10c),

9 increases downward from the surface to $1500 \mathrm{~m}$ depth before 2002 . The reason for this feature needs

10 to be investigated further. This may be related to the existence of slowly varying spatial salinity

11 patterns at these latitudes, which can be sample even with a limited set of observations. A large

12 value of the correlation is not synonymous of adequate sampling though. The influence of a few

13 deep observations may also persist for longer in the slowly varying deep ocean. Hence, the

14 relatively higher correlation in the deep Southern Ocean prior to Argo may be also an artefact of

15 using climatology in all the estimates, either as a prior in the OOAs, or as a nudging term in the

16 ORAs. There is a period of lower spatial correlations during 2003, probably associated with the

17 diversity of ways in which different systems adjust to the spin-up of Argo (including different

18 quality control decisions).Since 2003, the correlation in the Southern Ocean also increases over the

19 0-1000m depth, in particular over 0-400m depth after 2009, as Argo floats were deployed.

20 Generally, after Argo the CPCOR over the upper 0-500m of the ocean in both northern and

21 southern mid-latitude oceans are significantly smaller than that in the tropical oceans. This indicates

22 that there is still room for the salinity reanalyses in both northern and southern mid-latitude oceans

23 to be further improved and highlights the need for more Argo floats in this region. 
A phenomenon, which has been noticed by previous studies (Levitus et al. 2009; Xue et al.

2 2012; Balmaseda et al. 2015; Palmer et al. 2015) and announced by the IPCC (2013) and

3 operational or research centres

4 (http://www.epa.gov/climatechange/science/indicators/oceans/ocean-heat.html), is that the global averaged ocean heat content anomalies from either ORAs or OOAs have a growing trend from the 1990s till now. A similar growing trend has also been found in the steric sea level change (Levitus et al. 2012; also http://www.nodc.noaa.gov/OC5/3M_HEAT_CONTENT). This warming trend of ocean heat content anomalies has been considered as strong evidence for global warming in recent decades (IPCC 2013). Therefore, an interesting question is if the corresponding global averaged salinity anomalies retain a similar growing trend since the 1990s? If so, since the total salinity is approximately conserved in the global ocean, are the salinity anomalies that show a growing trend within a certain ocean layer compensated with a decreasing trend at other depths?

Fig. $11(\mathrm{a}-\mathrm{c})$ shows the temporal evolution of global averaged $\left(0-360^{\circ} \mathrm{E} ; 60^{\circ} \mathrm{S}-60^{\circ} \mathrm{N}\right)$ salinity anomalies (relative to climatology for the period 1993-2010), depth-averaged within 0-300m (i.e., S300; Fig.11a), 300-700m (i.e., S3-700; Fig.11b) and 700-1500m (i.e., S7-1500; Fig.11c) ocean layers, from all products for the period 1993-2010. It is worth noting that the depth-average in this study is calculated within 3 continuous vertical layers (i.e., 0-300m; 300-700m and 700-1500m) rather than the top to bottom vertical average (e.g., 0-300m, 0-700m and 0-1500m) approach used by Balmaseda et al. (2015). Therefore, we can show the different features of the trend in salinity anomalies within different vertical layers. In addition, the reference period for the climatology in this study (1993-2010) is different to the 1993-2007 period used by Balmaseda et al. (2015).

In the 0-300m upper ocean (Fig. 11a), the temporal evolution of global averaged S300 anomalies from all 3 OOAs, EMOO and EMORA show a growing trend similar to the corresponding global averaged temperature anomalies (not shown). However, the temporal evolutions of global averaged S300 anomalies among different ORAs are quite divergent and with a relatively large $U C R_{E M O R A}^{A}($ refer to the Eq. (A5)). For instance, SODA, GloSea5, ORAS3 and G2V3 
1 show rapidly growing trends after the beginning of Argo (2001), in contrast, PECDAS shows a

2 decreasing trend since the end of the 1990s and most other ORAs show weak decreasing and

3 increasing trends. In contrast, it can be seen from Fig.11b that the temporal evolution of the S3-700

4 anomalies from most ORAs shows a trend turning from generally increasing to decreasing after

5 2003. For all OOAs and a few ORAs, such as the ORAS4, CGLORS, there is no clear trend before

62003 followed by a very weak decreasing trend after 2003. This feature is quite different from that

7 of the corresponding global average temperature anomalies (not shown). Within the $700-1500 \mathrm{~m}$

8 depth layer, for the S7-1500 anomalies (Fig. 11c), most ORAs and OOAs, except for the G2V3,

9 ORAS4 and K7ODA, show a decreasing trend in the reference period, in particular after the

10 beginning of Argo.

11 Generally, the global averaged S300 anomalies from most ORAs and OOAs show a similar

12 growing trend in the reference period as that shown in corresponding global averaged temperature

13 anomalies, even though there is an increasing discrepancy of S300 anomalies among different

14 ORAs, in particular after the beginning of Argo. As the ocean depth increases, the global averaged

15 salinity anomalies from most ORAs and OOAs show a decreasing trend, in particular after Argo.

16 This feature can probably be explained by the approximate conservation of salt in the global ocean.

17 Interestingly, it can be seen from Figure 11 that most ORAs show a rapid change in both salinity

18 and temperature anomalies (not shown) after the beginning of Argo (i.e., 2002 or 2003). We note it

19 is more likely caused by the changes before and after Argo because of the shortage of reliable

20 observations of both salinity and temperature (in particular in the subsurface ocean) prior to the

21 Argo project.

\section{Conclusions}

In this paper, the reanalysed S700 of 14 ORAs from different institutions is assessed to address

25 the major agreement/disagreement among different ORAs. All ORAs assimilate both temperature and salinity observations using a variety of ocean models and assimilation methods. In addition, 
1 three OOAs are also used in this paper as independent data and reference for the assessment. The

2 ensemble spread about the multi-system ensemble mean is utilized to demonstrate the

3 agreement/disagreement and measure the uncertainty range among different ORAs.

Generally, the largest agreement (or smallest uncertainty range) of reanalysed S700 properties, such as mean state, standard deviation and correlation, among different ORAs occurred in the

6 tropical Pacific. The largest disagreement (or uncertainty range) was found in the Southern Ocean

7 along the ACC, and along the western boundary currents, such as the Kuroshio, Gulf Stream and

8 Brazil Current. The main cause for the disagreement in the Southern Ocean can be attributed to both

9 the shortage of ocean and atmospheric observations. Assimilation in the regions along the western

10 boundary currents, in particular the Gulf Stream, can be more difficult as noted by Balmaseda et al.

11 (2015) because the relatively stronger ocean fronts in these regions are not well simulated by the 12 ocean models.

13 It is shown that the variability of S700 anomalies (i.e., standard deviation) from most of the

14 ORAs is usually stronger over most parts of oceans compared with that from the OOAs. Moreover,

15 the standard deviation of EMORA is smaller than that of most individual ORAs over most parts of 16 oceans, except for the tropical Indian-Pacific Ocean. This is because there is relatively large phase 17 dispersion among different ORAs in these regions. Consequently, EMORA obtains the highest correlation of S700 anomalies with the corresponding EMOO when compared with that of each ORA. A $S N R$ value larger than one is mainly restricted to the WPWP region (probably because of the TAO/TRITON salinity observations), the central tropical Indian Ocean and a few parts of the

21 north Pacific and is associated with the regions with the smallest disagreement of S700 anomalies correlations among different ORAs.

Correlations between T700-S700 anomalies show coherent high values and consistent spatial patterns in both ORAs and OOAs products. The reason for this coherent large scale behaviour needs to be explored further. It may be caused by the temporal variations in availability of observations, which would affect ORAs and OOAs in similar manners. But it may be indicative of real dynamical 
1 signals associated to the large scale ocean circulation. Having good salinity estimations can thus

2 help us with the understanding and attribution of ocean variability.

The impact of Argo floats on the ocean reanalyses has been shown by some previous studies

4 (Balmaseda et al. 2007). In this study, our results demonstrated that the tropical oceans/Southern

5 Ocean have the largest/smallest improvement of salinity reanalyses during the Argo period.

6 Interestingly, the relatively large improvements in the salinity reanalyses due to Argo are mainly

7 confined within the upper 500m. It's probably because the models have better physics in the upper

8 ocean and therefore fit the Argo data in the upper ocean better. We note that the reason for this

9 phenomenon need to be further investigated in the future.

Although the assimilated global heat content anomalies within upper 700m from most ORAs

11 and OOAs show an increasing trend during the reference period 1993-2010 (refer to Palmer et al

12 2015), the global averaged salinity anomalies from most ORAs and OOAs only show an increasing trend within the top 0-300m layer, in particular in the Argo period. In contrast, in the other two layers beneath 300m (i.e., 300-700m; 700-1500m), the global averaged salinity anomalies from most ORAs and OOAs switch their trends from a slightly increasing trend prior to Argo to a decreasing trend after Argo. We note that there is a rapid change in the trend in global averaged salinity anomalies around 2002 likely due to Argo.

While there is some agreement regarding the spatial patterns of interannual variability of salinity and its relation with temperature, large uncertainty remains regarding global averaged salinity anomaly trends that will affect the estimation of global steric height (Zuo et al 2015). Since conservation of salt content is considered to be a good approximation, for diagnostic and attributions studies of global sea level it may be more pertinent to ignore the halo-steric component, 23 rather than using unreliable halo-steric trends from ORAs. However, the ORA estimation of the thermo-steric component appears to be more robust (Storto et al, 2015).

Finally, despite the progresses in salinity reanalyses made by most state-of-the-art ORAs, we note that the current performance of salinity reanalyses from most ORAs is still a long way from 
1 being considered a satisfactory and reliable estimation. As mentioned above, the relatively large

2 disagreement/agreement in reanalysed salinity among the different ORAs offers a useful guidance

3 to potential users and scientists. These results highlight ocean regions where the salinity reanalyses

4 may be more reliable (e.g., the tropical Pacific Ocean) and which regions the salinity reanalyses

5 need to be improved (e.g., the Southern Ocean and regions along the western boundary currents).

6 Sustaining and enhancing oceanic measurements of salinity such as those derived from Argo and

7 satellites (e.g., European Space Agency's Soil Moisture and Ocean Salinity and NASA's Aquarius

8 missions) and improving evaporation and precipitation products (e.g., from atmospheric reanalysis)

9 are important to improving the representation of salinity by ORAs in the future. It is also worth

10 noting that the impacts of the ocean models and assimilation techniques on the improvement of

11 salinity reanalyses are also important. 


\section{APPENDIX}

4 In this study, the $X_{n}^{A}$ represents the anomaly (seasonal cycle removed) of corresponding total

5 variable $X_{n}$ for individual $n$ ORA. Thus, the multi-system ensemble mean (i.e., EMORA) of $X_{n}$ or

$6 \quad X_{n}^{A}$ from the 14 ORAs can be given by:

$$
\overline{X_{E M O R A}}=\frac{1}{n s y s} \sum_{n=1}^{n s y s} X_{n} \quad \text { or } \quad \overline{X_{E M O R A}^{A}}=\frac{1}{n s y s} \sum_{n=1}^{n s y s} X_{n}^{A}
$$

8 The $n s y s$ represents the total number of all ORAs for calculating EMORA (nsys $=14)$. The

9 corresponding $\overline{X_{E M O O}}$ or $\overline{X_{E M O O}^{A}}$ can be similarly calculated by the Eq. (A1) except for the $X_{n}$ or $X_{n}^{A}$

10 of individual $n$ OOA and $n s y s=3$.

11 b. Ensemble spread (SPD)

12 The ensemble spread of different variables $X$ from 14 ORAs about their corresponding EMORA

13 shown in Fig. 1c, $6 \mathrm{~b}$ and $8 \mathrm{c}$ is given by:

$$
\operatorname{SPD}_{E M O R A}^{X}(i, j)=\sqrt{\frac{1}{n s y s} \sum_{n=1}^{n S y s}\left(X_{n}(i, j)-\overline{X_{E M O R A}}(i, j)\right)^{2}}
$$

15 Here, the $X$ represents the annual mean (AM) of $S 700$ in Fig. 1c (i.e., $S P D_{E M O R A}^{A M}$ ), the correlation

16 of $\mathrm{S} 700$ anomalies in Fig. $6 \mathrm{~b}$ and the correlation of T700-S700 anomalies in Fig.8c (i.e., $S P D_{E M O R A}^{C O R}$ ),

17 respectively. The $i / j$ represents the longitude/latitude, respectively.

18 Similarly, the $\operatorname{SPD}_{E M O R A}^{A}(i, j)$, that is shown in Fig. 5a, can be calculated as:

$$
S P D_{\text {EMORA }}^{A}(i, j)=\sqrt{\frac{1}{\text { mons }} \sum_{t=1}^{\text {mons }} \frac{1}{n s y s} \sum_{n=1}^{n s y s}\left(X_{n}^{A}(i, j, t)-\overline{X_{\text {EMORA }}^{A}}(i, j, t)\right)^{2}}
$$


1 Here, the $X_{n}^{A}(i, j, t)$ denotes the $\mathrm{S} 700$ anomalies for individual $n$ ORA. The mons is the total

2 number of months for the variable $X$ (i.e., mons $=216$ for the period 1993-2010).

3

4 c. Uncertainty range (UCR)

5 The uncertainty range (i.e., the shaded band shown in Fig. 2) of the meridionally-averaged

6 AMS700 (i.e., $X$ ) from 14 ORAs about their corresponding EMORA (i.e., $\overline{X_{E M O R A}}$ ) is defined as:

$7 \quad U C R_{E M O R A}^{A M}(i)=\overline{X_{E M O R A}}(i) \pm S P D_{E M O R A}^{A M}(i)$

8 Here, the $S P D_{E M O R A}^{A M}(i)$ can be calculated by the Eq. (2) but without the dimension $j$. The $U C R$

9 shown in Fig. 4, Fig. 7 and Fig. 9 can be similarly calculated by the Eq. (A4) except that the

10 variable $X$ should be replaced by standard deviation for Fig.4, the correlation coefficients for Fig. 7

11 and Fig. 9, respectively. In addition, the $U C R$ shown in Fig. 3, where the $X$ represents the seasonal 12 cycle of S700, can be also calculated by the Eq. (A4) except for replacing the dimension $i$ by the

13 dimension $t$.

14 The $U C R_{E M O R A}^{A}(z, t)$ shown in Fig. 11 is given by:

15

$$
\operatorname{UCR}_{E M O R A}^{A}(z, t)=\overline{X_{E M O R A}^{A}}(z, t) \pm S P D_{E M O R A}^{A}(z, t)
$$

16 Here, the $\overline{X_{E M O R A}^{A}}(z, t)$ denotes the global averaged salinity anomaly in different ocean layers $z$ for

17 EMORA. And, the $\operatorname{SPD}_{E M O R A}^{A}(z, t)$ is calculated as:

$$
\operatorname{SPD}_{\text {EMORA }}^{A}(z, t)=\sqrt{\frac{1}{n s y s} \sum_{n=1}^{n s y s}\left(X_{n}^{A}(z, t)-\overline{X_{E M O R A}^{A}}(z, t)\right)^{2}}
$$

Here, the $X_{n}^{A}(z, t)$ denotes the global averaged salinity anomaly in different ocean layers $z$ for the individual $n$ ORA.

c. Standard deviation (STD) 
$2 \operatorname{STD}_{n}^{A}(i)$ ) and the corresponding EMORA (i.e., $S T D_{E M O R A}^{A}(i)$ ), which is shown in Fig. 4, is respectively

3 given by:

$4 \quad \operatorname{STD}_{n}^{A}(i)=\sqrt{\frac{1}{\text { mons }} \sum_{t=1}^{\text {mons }}\left(X_{n}^{A}(i, t)\right)^{2}}$

5 and

$6 \quad \operatorname{STD}_{\text {EMORA }}^{A}(i)=\sqrt{\frac{1}{\text { mons }} \sum_{t=1}^{\text {mons }}\left(\overline{X_{\text {EMORA }}^{A}}(i, t)\right)^{2}}$

7 The corresponding $S T D_{E M O O}^{A}(i)$ in Fig. 4 can be similarly calculated by the Eq. (A8) except for

8 replacing the $\overline{X_{E M O R A}^{A}}(i, t)$ by the $\overline{X_{E M O O}^{A}}(i, t)$. Additionally, the STD of S700 anomaly for EMORA (i.e.,

$\left.9 \operatorname{STD}_{\text {EMORA }}^{A}(i, j)\right)$, which is shown in Fig. 5b, can be also calculated by Eq. (A8) except for adding the

$10 \operatorname{dimension} j$.

\section{d. Centred pattern correlation (CPCOR)}

13 The centred pattern correlation (i.e., $\operatorname{CPCOR}(z t)$ ) of salinity anomalies (seasonal cycle removed)

14 between EMORA (i.e., $\left.\overline{X_{E M O R A}^{A}}(i, j, z, t)\right)$ and EMOO (i.e., $\left.\overline{X_{E M O O}^{A}}(i, j, z, t)\right)$ as a function of depth $(0$ -

15 1500m) and time (1993-2010), which is shown in Fig. 10, is defined as:

$\left.16 \operatorname{CPCOR}(z, t)=\left[\frac{1}{m \times n} \sum_{j=1}^{n} \sum_{i=1}^{m}\left(\left(\overline{X_{\text {EMORA }}^{A}}(i, j, z, t)-M_{\text {EMORA }}\right) \overline{X_{\text {EMOO }}^{A}}(i, j, z, t)-M_{E M O O}\right)\right)\right] /\left(S_{\text {EMORA }} S_{\text {EMOO }}\right)$

17 Here, the $m / n$ denotes total longitude/latitude grids of the calculated ocean band. The $M_{\text {EMORA }} /$

$18 M_{\text {ЕмоO }}$ denotes the total mean of the $\overline{X_{\text {ЕмоRA }}^{A}}(i, j, z, t) / \overline{X_{\text {ЕмоO }}^{A}}(i, j, z, t)$ over the calculated ocean band,

19 respectively. Thus, the $M_{E M O R A}$ can be given by: 
$1 \quad M_{\text {EMORA }}=\frac{1}{m \times n} \sum_{j=1}^{n} \sum_{i=1}^{m} \overline{X_{E M O R A}^{A}}(i, j, z, t)$

2 Thus, the $M_{E M O O}$ can be similarly calculated by the Eq. (A10) except for replacing the $\overline{X_{E M O R A}^{A}}$ by 3 the $\overline{X_{E M O O}^{A}}$. The $S_{E M O R A} / S_{E M O O}$ in Eq. (A10) denotes the spatial standard deviations of the $\overline{X_{E M O R A}^{A}} /$

$4 \overline{X_{E M O O}^{A}}$, respectively. The $S_{E M O R A}$ can be obtained by:

$5 \quad S_{\text {EMORA }}(z, t)=\sqrt{\frac{1}{m \times n} \sum_{j=1}^{n} \sum_{i=1}^{m}\left(\overline{X_{E M O R A}^{A}}(i, j, z, t)-M_{E M O R A}\right)^{2}}$

6 The corresponding $S_{E M O O}$ can be also obtained by the Eq. (A11) except for replacing the $\overline{X_{E M O R A}^{A}}$

7 by the $\overline{X_{E M O O}^{A}}$.

8 


\section{Reference}

Ballabrera-Poy, J., R. Murtugudde, and A. J. Busalacchi, 2002: On the potential impact of sea surface salinity observations on ENSO predictions, J. Geophys. Res., 107(C12), 8007, doi:10.1029/2001JC000834

Balmaseda, M.A., D. Anderson, and A. Vidard, 2007: Impact of Argo on analyses of the global ocean, Geophys. Res. Lett., 34, L16605, doi:10.1029/2007GL030452.

Balmaseda, M. A., A. Vidard, and D. Anderson, 2008: The ECMWF ORA-S3 ocean analysis system. Mon. Wea. Rev., 136, 3018-3034.

Balmaseda M. A, O. J. Alves, A. Arribas, T. Awaji, D.W. Behringer, N. Ferry, Y. Fujii, T. Lee, M. Rienecker, T. Rosati, and D. Stammer, 2009: Ocean initialization for seasonal forecasts. Oceanography, 22, 154-159.

Balmaseda M.A., K. Mogensen, A. Weaver, 2013: Evaluation of the ECMWF Ocean Reanalysis ORAS4. Q. J. R. Meteor. Soc., 139.1132-1161.

Balmaseda M.A., and Co-authors, 2015: The Ocean Reanalyses Intercomparison Project (ORA-IP). J. Operational Oceanography, 7, 81-99.

Behringer, D. W., and Y. Xue, 2004: Evaluation of the global ocean data assimilation system at NCEP: The Pacific Ocean. Eighth Symposium on Integrated Observing and Assimilation Systems for Atmosphere, Oceans, and Land Surface, AMS 84th Annual Meeting, Washington State Convention and Trade Center, Seattle, Washington, 11-15 Jan.

Belkin, I. M., S. Levitus, J. Antonov, and S. A. Malmberg, 1998: "Great Salinity Anomalies" in the North Atlantic. Prog. Oceanogr., 41, 1-68.

Belkin, I. M., 2004: Propagation of the "Great Salinity Anomaly" of the 1990s around the northern North Atlantic. Geophys. Res. Lett., 31, L08306, doi:10.1029/2003GL019334.

Boyer, T. P., S. Levitus, I. Antonov, R. A. Locarnini, and H. E. Garcia, 2005: Linear trends in salinity for the World Ocean, 1955-1998. Geophys. Res. Lett., 32, L01604, doi:10.1029/2004GL021791. 
1 Carton, J. A., and B. S. Giese, 2008: A reanalysis of ocean climate using Simple Ocean Data

2 Assimilation (SODA), Mon. Wea. Rev., 136, 2999-3017.

3 Chang, Y.-S., S. Zhang, A. Rosati, T. Delworth, and W. F. Stern, 2012: An assessment of oceanic variability for 1960-2010 from the GFDL ensemble coupled data assimilation, Clim. Dyn., doi:10.1007/s00382-012-1412-2

Cooper, N. S., 1988: The effect of salinity on tropical ocean model. J. Phys. Oceanography. 18, 697-707.

Cronin, M. F., and M. J. McPhaden, 1998: Upper ocean salinity balance in the western equatorial Pacific, J. Geophys. Res., 103, 27567-27588.

Curry, R., B. Dickson, and I. Yashayaev, 2003: A change in the freshwater balance of the Atlantic Ocean over the past four decades. Nature, 426, 826-829.

Dickson, R. R., J. Meincke, S.A. Malmberg, and A. J. Lee, 1988: The "Great Salinity Anomaly" in the northern North Atlantic, 1968-1982. Prog. Oceanogr., 20, 103-151.

Durack, P. J., and S. E. Wijffels, 2010: Fifty-year trends in global ocean salinities and their relationship to broad-scale warming. J. Climate, 23, 4342-4362.

Durack, P. J., S. E. Wijffels, and R. J. Matear, 2012: Ocean salinities reveal strong global water cycle intensification during 1950 to 2000 . Science, 336, 455-458.

Fedorov, A. V., R. C. Pacanowski, S. G. Philander, and G. Boccaletti, 2004: The effect of salinity on the wind-driven circulation and the thermal structure of the upper ocean. J. Phys. Oceanography.34, 1949-1966.

Foltz, G. R., S. A. Grodsky, and J. A. Carton, 2004: Seasonal salt budget of the north western tropical Atlantic Ocean along $38^{\circ}$ W. J. Geophys. Res., 109, C03052, doi:10.1029/2003JC002111.

Fujii, Y., T. Nakaegawa, S. Matsumoto, T. Yasuda, G. Yamanaka, and M. Kamachi, 2009: Coupled 5 Climate Simulation by Constraining Ocean Fields in a Coupled Model with Ocean Data. J. Climate, 22, 5541-5557. 
1 Fujii, Y., M. Kamachi, S. Matsumoto, and S. Ishizaki, 2012: Barrier layer and relevant variability of the salinity field in the equatorial Pacific estimated in an ocean reanalysis experiment. Pure Appl. Geophys.169 (3), 579-594.

Guinehut, S., A.-L. Dhomps, G. Larnicol and P.-Y. Le Traon, 2012: High resolution 3D temperature and salinity fields derived from in situ and satellite observations. Ocean Sci., 8, 845-857.

Hackert, E., J. Ballabrera-Poy, A. Busalacchi, R.H. Zhang, and R. Murtugudde, 2011: Impact of sea surface salinity assimilation on coupled forecasts in the tropical Pacific, J. Geophys. Res., 116, C05009, doi:10.1029/2010JC006708.

Held, I. M., and B. J. Soden, 2006: Robust responses of the hydrological cycle to global warming. $J$. Climate, 19, 5686-5699.

Hernandez, F., L. Bertino, G. Brassington, E. Chassignet, J. Cummings, F. Davidson, M. Drévillon, G. Garric, M. Kamachi, J.-M. Lellouche, R. Mahdon, M.J. Martin, A. Ratsimandresy, and C. Regnier, 2009: Validation and intercomparison studies within GODAE. Oceanography 22(3):128-143.

Huang, B., Y. Xue, and D.W. Behringer, 2008: Impacts of Argo salinity in NCEP global ocean data assimilation system: The tropical Indian Ocean. J. Geophys. Res., 113, C08002, doi:10.1029/ 2007JC004388

Ingleby, B., and M. Huddleston, 2007: Quality control of ocean temperature and salinity profiles historical and real-time data. J. Marine Sys., 65, 158-175.

IPCC (Intergovernmental Panel on Climate Change) 2013, Climate change 2013: The physical science basis. Working Group I contribution to the IPCC Fifth Assessment Report. Cambridge, United Kingdom: Cambridge University Press (see www.ipcc.ch/report/ar5/wg1).

Janowiak, J. E., P. Bauer, W. Wang, P. A. Arkin, and J. Gottschalck, 2010: An Evaluation of Precipitation Forecasts from Operational Models and Reanalyses Including Precipitation Variations Associated with MJO Activity. Mon. Wea. Rev., 138, 4542-4560. 
1 Johnson, E. S., G. S. E. Lagerloef, J. T. Gunn, and F. Bonjean, 2002: Salinity advection in the tropical oceans compared to atmospheric forcing: A trial balance, J. Geophys. Res., 107, 8014.

Kim, J.-E., and M. J. Alexander, 2013: Tropical Precipitation Variability and Convectively Coupled Equatorial Waves on Submonthly Time Scales in Reanalyses and TRMM. J. Climate, 26, 3013-3030.

Lee, T., T. Awaji, M.A. Balmaseda, E. Greiner, and D. Stammer, 2009: Ocean state estimation for climate research. Oceanography, 22(3):160-167.

Levitus, S., J. I. Antonov, T. P. Boyer, R. A. Locarnini, H. E. Garcia, and A.V. Mishonov, 2009: Global ocean heat content 1955-2008 in light of recently revealed instrumentation problems, Geophys. Res. Lett., 36, L07608, doi:10.1029/2008GL037155

Levitus, S., J. I. Antonov, T. P. Boyer, O. K. Baranova, H. E. Garcia, R. A.Locarnini, A. V. Mishonov, J. R. Reagan, D. Seidov, E. S. Yarosh, M. M. Zweng, 2012: World Ocean heat content and thermosteric sea level change (0-2000 m)1955-2010. Geophys. Res. Lett., 39, L10603, doi:10.1029/2012GL051106.

O'Kane, T. J., R. J. Matear, M. A. Chamberlain, and P. R. Oke, 2014: ENSO regimes and the late 1970's climate shift: The role of synoptic weather and South Pacific Ocean spiciness. J. Comp. Phy., 271, 19-38.

Maes, C., J. Picaut, and S. Belamari, 2005: Importance of salinity barrier layer for the buildup of El Niño. J. Climate, 18, 104- 118.

Maes, C., K. Ando, T. Delcroix, W. S. Kessler, M. J. McPhaden, and D. Roemmich, 2006: Observed correlation of surface salinity, temperature and barrier layer at the eastern edge of the western Pacific warm pool. Geophys. Res. Lett., 33, L06601, doi: 10.1029/2005GL024772.

Marshall, J., A. Adcroft, C. Hill, L. Perelman, and C. Helsey, 1997: A finite-volume, incompressible Navier-Stokes model for studies of the ocean on parallel computers. J. Geophys. Res., 102, 5753-5766 
1 Masuda, S., and Co-authors, 2010: Simulated Rapid Warming of Abyssal North Pacific Waters. Science, 329, 319-322

3 Murtugudde, R., and A. J. Busalacchi 1998: Salinity effects in a tropical ocean model. J. Geophys. Res., 103, 3282-3300.

Palmer, M., and Co-authors, 2015: Ocean heat content variability and change in an ensemble of ocean reanalyses. Submitted to the Climate Dynamic

Rahmstorf, S., 1996: On the freshwater forcing and transport of the Atlantic thermohaline circulation. Clim. Dyn., 12, 799-811

Santer, B.D., T.M.L. Wigley, and P.D. Jones, 1993: Correlation methods in fingerprint detection studies. Clim. Dyn., 8, 265-276.

11 Sprintall, J., S. E. Wijffels, R. Molcard, and I. Jaya, 2009: Direct estimates of the Indonesian Throughflow entering the Indian Ocean: 2004-2006. J. Geophy. Res-Oce., 114, C07001, doi:10.1029/2008JC005257

Storto, A., S. Dobricic, S. Masina, and P. Di Pietro, 2011: Assimilating along-track altimetric observations through local hydrostatic adjustments in a global ocean reanalysis system. Mon. Wea. Rev., 139, 738-754.

Storto, A., and Co-authors, 2015: Steric sea level variability (1993-2010) in an ensemble of ocean reanalyses and objective analyses. Submitted to the Climate Dynamic

Toyoda, T, Y. Fujii, T. Yasuda, N. Usui, T. Iwao, T. Kuragano, and M. Kamachi, 2013: Improved analysis of the seasonal-interannual fields by a global ocean data assimilation system, Theoretical and Applied Mechanics Japan, 61, 31-48.

Vernieres, G., M. M. Rienecker, R. Kovach, and L. C. Keppenne, 2012: The GEOS-iODAS: Description and evaluation. Tech. Rep. TM-2012-104606, NASA, National Aeronautics and Space Administration Goddard Space Flight Center, Greenbelt, Md. 
1 Vialard, J., P. Delecluse, and C. Menkes, 2002: A modelling study of salinity variability and its

2 effects in the tropical Pacific Ocean during the 1993-1999 period. J. Geophys. Res., 107, C12, $3 \quad 8005$, doi:10.1029/2000JC000758

4 Vinje, T., 2001: Fram Strait ice fluxes and atmospheric circulation, 1950-2000. J. Climate. 14, $5 \quad 3508-3517$

6 von Storch, H., and A. Navarra, 1999: Analysis of climate variability: applications of statistical $7 \quad$ techniques. Published by Springer-Verlag Berlin.

8 Vranes, K., A. L. Gordon, and A. Ffield, 2002: The heat transport of the Indonesian throughflow and implications for Indian Ocean heat budget. Deep-Sea Research I II, 49, 1391-1410.

Wadley, M. R., G. R. Bigg, 2006: Are “Great Salinity Anomalies” advective? J. Climate, 19, 10801088.

Wang, X., and Y. Chao, 2004: Simulated sea surface salinity variability in the tropical Pacific. Geophys. Res. Lett., 31, L02302, doi:10.1029/2003GL01

Waters J, Martin M, While J, Lea D, Weaver A, and Mirouze I. 2014: Implementing a variational data assimilation system in an operational $1 / 4$ degree global ocean model. Q. J. R. Meteorol. Soc. DOI: $10.1002 / \mathrm{qj} .2388$

Xue Y., and Co-authors, 2011: An assessment of oceanic variability in the NCEP climate forecast reanalysis. Clim. Dyn., 37, 2511-2539

Xue Y., and Coauthors, 2012: A Comparative Analysis of Upper-Ocean Heat Content Variability from an Ensemble of Operational Ocean Reanalyses. J. Climate, 25, 6905-6929.

Yang, S. C., M. Rienecker, and C. Keppenne, 2010: The impact of ocean data assimilation on seasonal-to-interannual forecasts: A case study of the 2006 El Niño event. J. Climate, 23, 40804095.

Yin, Y., O. Alves, and P. R. Oke, 2011: An ensemble ocean data assimilation system for seasonal prediction. Mon. Wea. Rev., 139, 786-808. 
1 Zhao, M., H. H. Hendon, O. Alves, Y. Yin, and D. Anderson, 2013: Impact of salinity constraints on the simulated mean state and variability in a coupled seasonal forecast model. Mon. Wea.

3 Rev., 141, 388-402.

4 Zhao, M., H. H. Hendon, O. Alves, and Y. Yin, 2014: Impact of improved assimilation of temperature and salinity for coupled model seasonal forecasts, Clim. Dyn., 42, 2565-2585

6 Zhang, R., and G. K. Vallis, 2006: Impact of great salinity anomalies on the low-frequency variability of the north Atlantic climate. J. Climate, 19, 470-482.

Zhang S., M. J. Harrison, A. Rosati, and A. Wittenberg, 2007: System design and evaluation of coupled ensemble data assimilation for global oceanic studies. Mon. Wea. Rev., 135, 3541-3564.

10 Zhu, J., B. Huang, and M. Balmaseda, 2012: An ensemble estimation of the variability of upper11 ocean heat content over the tropical Atlantic Ocean with multi-ocean reanalysis products. Clim. Dyn. 39, 1001-1020.

13 Zhu, J., B. Huang, R.-H. Zhang, Z.-Z. Hu, A. Kumar, M. A. Balmaseda, L. Marx and J. L. Kinter III, 2014: Salinity anomaly as a trigger for ENSO events. Nature, scientific report, 4 : 6821, doi: $10.1038 /$ srep06821

Zuo, H., Balmaseda, M. A. and Mogensen, K., 2015. The new eddy-permitting ORAP5 ocean reanalysis: description, evaluation and uncertainties in climate signals. Clim. Dyn., $10.1007 / \mathrm{s} 00382-015-2675-1$ 
Table 1: List of the ocean data assimilation systems

\begin{tabular}{|c|c|c|c|c|c|}
\hline Products & Ocean Models & Forcing & Main Assim. Method & Data Assimilated & Relax to Clim. \\
\hline $\begin{array}{c}\mathbf{E C C O V 4}^{\mathbf{a})} \\
(\mathrm{MIT} / \mathrm{AER} / \mathrm{JPL}))\end{array}$ & $\begin{array}{c}\text { MITGCM } \\
1^{\circ} \times\left(0.4-1.0^{\circ}\right) ; 50 \text { vertical levels }\end{array}$ & ERAi + CORE Bulk & 4DVAR Adjoint & T/S; SLA; SSH; SST & None \\
\hline $\begin{array}{c}\text { GMAO }^{\mathbf{b})} \\
\text { GSFC/NASA }\end{array}$ & $\begin{array}{c}\text { MOM4p1 } 1 \\
0.5^{\circ} ; 40 \text { vertical levels }\end{array}$ & MERRA + Bulk & EnOI & T/S; SST; & SSS \\
\hline $\begin{array}{c}\text { SODA }^{\mathbf{c})} \\
\text { Uni. Maryland and TAMU }\end{array}$ & $\begin{array}{c}\text { POP2. } 1 \\
0.25^{\circ} \times 0.4^{\circ} ; 40 \text { vertical levels }\end{array}$ & ERA40 and ERAi (since 2002) + Bulk & OI & $\mathrm{T} / \mathrm{S} ; \mathrm{SST}$ & $\begin{array}{l}\text { SSS ( } 3 \text { months); 3D } \\
\text { T/S (10 years) }\end{array}$ \\
\hline $\begin{array}{c}\text { GloSea5 }{ }^{\mathbf{d})} \\
\text { Met Office, UK }\end{array}$ & $\begin{array}{c}\text { NEMO3.2 } \\
1 / 4^{\circ} ; 75 \text { vertical levels }\end{array}$ & ERAi + CORE Bulk & 3DVAR & T/S; SST; SLA; SIC & $\begin{array}{c}\text { Surface Haney } \\
\text { restoring + 3D T/S } \\
(360 \text { days })\end{array}$ \\
\hline $\begin{array}{l}\text { ORAS3 }^{\text {e) }} \\
\text { ECMWF }\end{array}$ & $\begin{array}{c}\text { HOPE } \\
1^{\circ} \times\left(0.3-1^{\circ}\right) ; 29 \text { vertical levels }\end{array}$ & $\begin{array}{l}\text { ERA40 and ECMWF operational analysis } \\
\text { (since 2002) }\end{array}$ & OI & T/S; SST; SLA & $\begin{array}{l}\text { SSS ( } 3 \text { years); 3D } \\
\text { T/S (10 years) }\end{array}$ \\
\hline $\begin{array}{l}\text { ORAS4 }^{\text {f) }} \\
\text { ECMWF }\end{array}$ & $\begin{array}{c}\text { NEMO3.0 } \\
1^{\circ} \times 1^{\circ} ; 42 \text { vertical levels }\end{array}$ & ERA40 to 1988 , ERAi thereafter + Flux & 3DVAR & T/S; SST; SLA & $\begin{array}{l}\text { SSS ( } 1 \text { year }) ; 3 \mathrm{D} \\
\mathrm{T} / \mathrm{S} \text { ( } 20 \text { years })\end{array}$ \\
\hline $\begin{array}{l}\left.\text { CGLORS }^{\mathbf{g}}\right) \\
\text { CMCC/IT }\end{array}$ & $\begin{array}{c}\text { NEMO3.2.1-LIM2 } \\
0.5^{\circ} \times 0.5^{\circ} ; 50 \text { vertical levels }\end{array}$ & ERAi + CORE Bulk & 3DVAR & T/S; SLA; SST; SIC & $\begin{array}{l}\text { SSS (300 days); 3D } \\
\text { T/S }\end{array}$ \\
\hline $\begin{array}{l}\text { PEODAS } \\
\text { BOM/AUS }\end{array}$ & $\begin{array}{c}\text { MOM2 } \\
2^{\circ} \times\left(0.5-1.5^{\circ}\right) ; 25 \text { vertical levels }\end{array}$ & ERA40 and NCEP2 (since 2002) & EnKF & $\mathrm{T} / \mathrm{S} ; \mathrm{SST}$ & $\begin{array}{l}\text { SSS }(1 \text { year }) ; 3 \mathrm{D} \\
\mathrm{T} / \mathrm{S}(2 \text { years })\end{array}$ \\
\hline $\begin{array}{l}\text { PECDAS } \\
\text { BOM/AUS }\end{array}$ & $\begin{array}{c}\text { MOM2 } \\
2^{\circ} \times\left(0.5-1.5^{\circ}\right) ; 25 \text { vertical levels }\end{array}$ & Atmospheric component of the coupled model & EnKF & $\mathrm{T} / \mathrm{S} ; \mathrm{SST}$ & $\begin{array}{l}\text { SSS }(1 \text { year }) ; 3 \mathrm{D} \\
\mathrm{T} / \mathrm{S}(2 \text { years })\end{array}$ \\
\hline $\begin{array}{c}\text { ECDA }^{\mathbf{i})} \\
\text { GFDL/NOAA }\end{array}$ & $\begin{array}{c}\mathrm{CM} 2.1 / \mathrm{MOM} 4 \\
1^{\circ} \times\left(0.3-1^{\circ}\right) ; 50 \text { vertical levels }\end{array}$ & Atmospheric component of the coupled model & EnKF & $\mathrm{T} / \mathrm{S} ; \mathrm{SST}$ & None \\
\hline $\begin{array}{l}\text { MOVE-C } \\
\text { MRI/JMA }\end{array}$ & $\begin{array}{c}\text { MRI.COM V2 } \\
1^{\circ} \times\left(0.3-1.0^{\circ}\right) ; 50 \text { vertical levels }\end{array}$ & Atmospheric component of the coupled model & MOVE 3DVAR-IAU & T/S; SSH; SST & $\begin{array}{l}\text { SSS }(10 \text { days }) ; 3 \mathrm{D} \\
\mathrm{T} / \mathrm{S}(5 \text { years })\end{array}$ \\
\hline $\begin{array}{l}\text { MOVE-G2 } \\
\text { (MRI/JMA) }\end{array}$ & $\begin{array}{c}\text { MRI.COM V3 } \\
1^{\circ} \times\left(0.3-0.5^{\circ}\right) ; 52 \text { vertical levels }\end{array}$ & JRA-55 CORE Bulk & MOVE 3DVAR-FGAT-IAU & T/S; SSH; SST & 3D T/S (5 years) \\
\hline 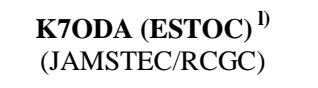 & $\begin{array}{l}\text { MOM3-based OGCM } \\
1^{\circ} \times 1^{\circ} ; 45 \text { vertical levels }\end{array}$ & NCEP-R1 + Corr. Flux & 4DVAR Adjoint & T/S; SLA; SST & $\mathrm{BC}(30$ days by IAU) \\
\hline $\begin{array}{c}\mathbf{G 2 V 3} \\
\text { Mercator Océan/FR }\end{array}$ & $\begin{array}{l}\text { NEMO3.1-LIM2evp } \\
1 / 4^{\circ} ; 75 \text { vertical levels }\end{array}$ & ERAi Corr + CORE Bulk & SAM2V1 - SEEK filter + 3DVAR & T/S; SLA; SST; SIC & 3D T/S (360 days) \\
\hline $\begin{array}{l}\text { ARMOR3D }^{\mathbf{m})} \\
\text { CLS/FR }\end{array}$ & $\begin{array}{c}\text { No Model } \\
1 / 3^{\circ} ; 24 \text { vertical levels }\end{array}$ & N/A & Objective Analysis & T/S; SLA; SST & None \\
\hline
\end{tabular}




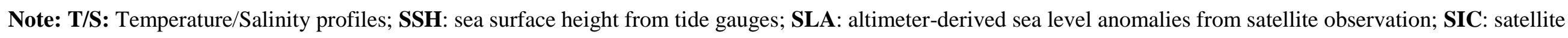

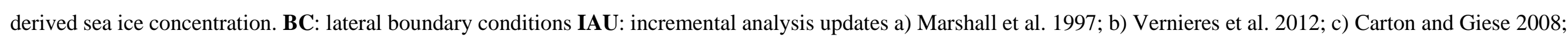

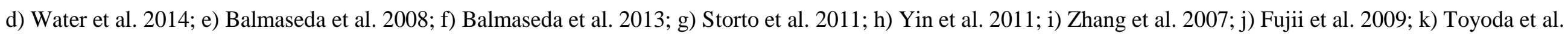
2013; 1) Masuda et al. 2010; m) Guinehut et al. 2012; o) Ingleby and Huddleston 2007 

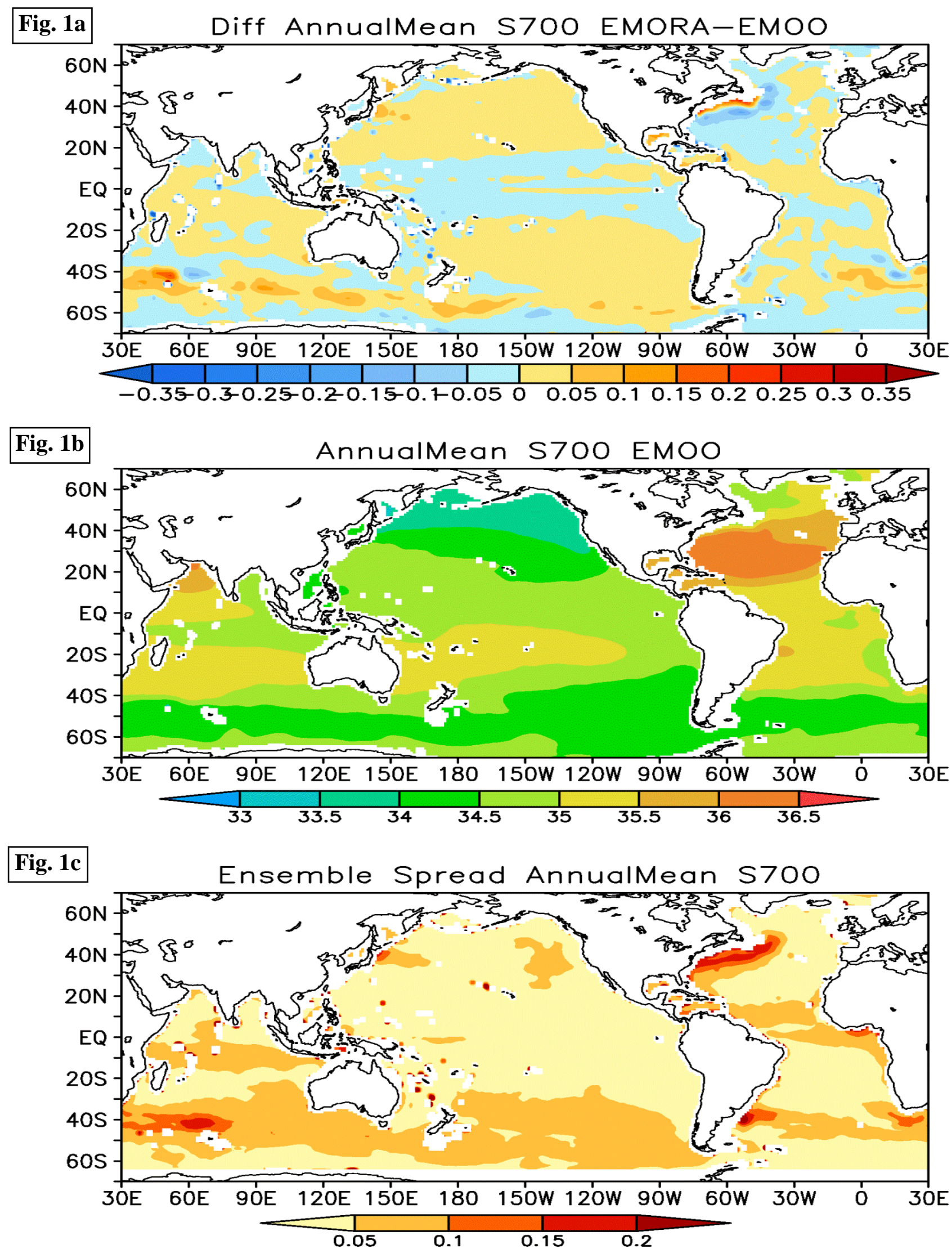

Fig. 1: (a) Differences of the annual mean S700 (AMS700) between the ensemble mean of ORAs (EMORA) and the ensemble mean of 3 OOAs (EMOO) for the period 1993-2010. (b) The distribution of AMS700 from EMOO for the period 1993-2010. (c) The ensemble spread (i.e. $S P D_{E M O R A}^{A M}$ ) of AMS700 from individual ORAs about the corresponding EMORA. The unit of colour bar is $p s u$. 


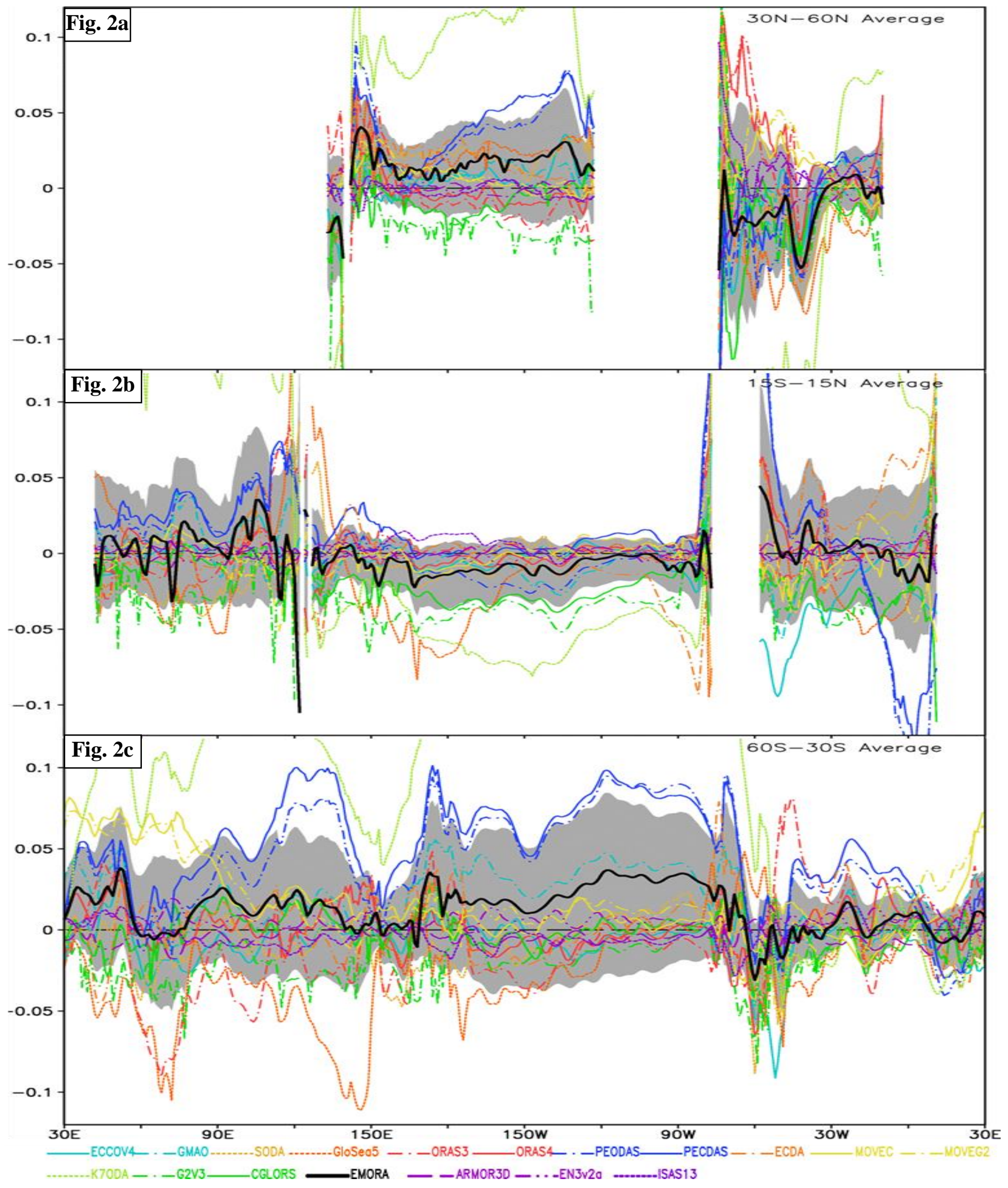

Fig. 2: (a) Zonal distributions of differences of meridionally-averaged (over $30^{\circ} \mathrm{N}-60^{\circ} \mathrm{N}$ ) AMS700 between individual reanalysis systems and EMOO for the period 1993-2010. The definition of shaded band (i.e. $U_{C R}^{A M}{ }_{E M A}$ ) can be referred to the Eq. (A4). b) Same as in (a), except for meridionally-averaged over $15^{\circ} \mathrm{S}-15^{\circ} \mathrm{N}$. (c) Same as in (a), except for meridionally-averaged over $60^{\circ} \mathrm{S}-30^{\circ} \mathrm{S}$. The unit of ordinate is $p s u$. 


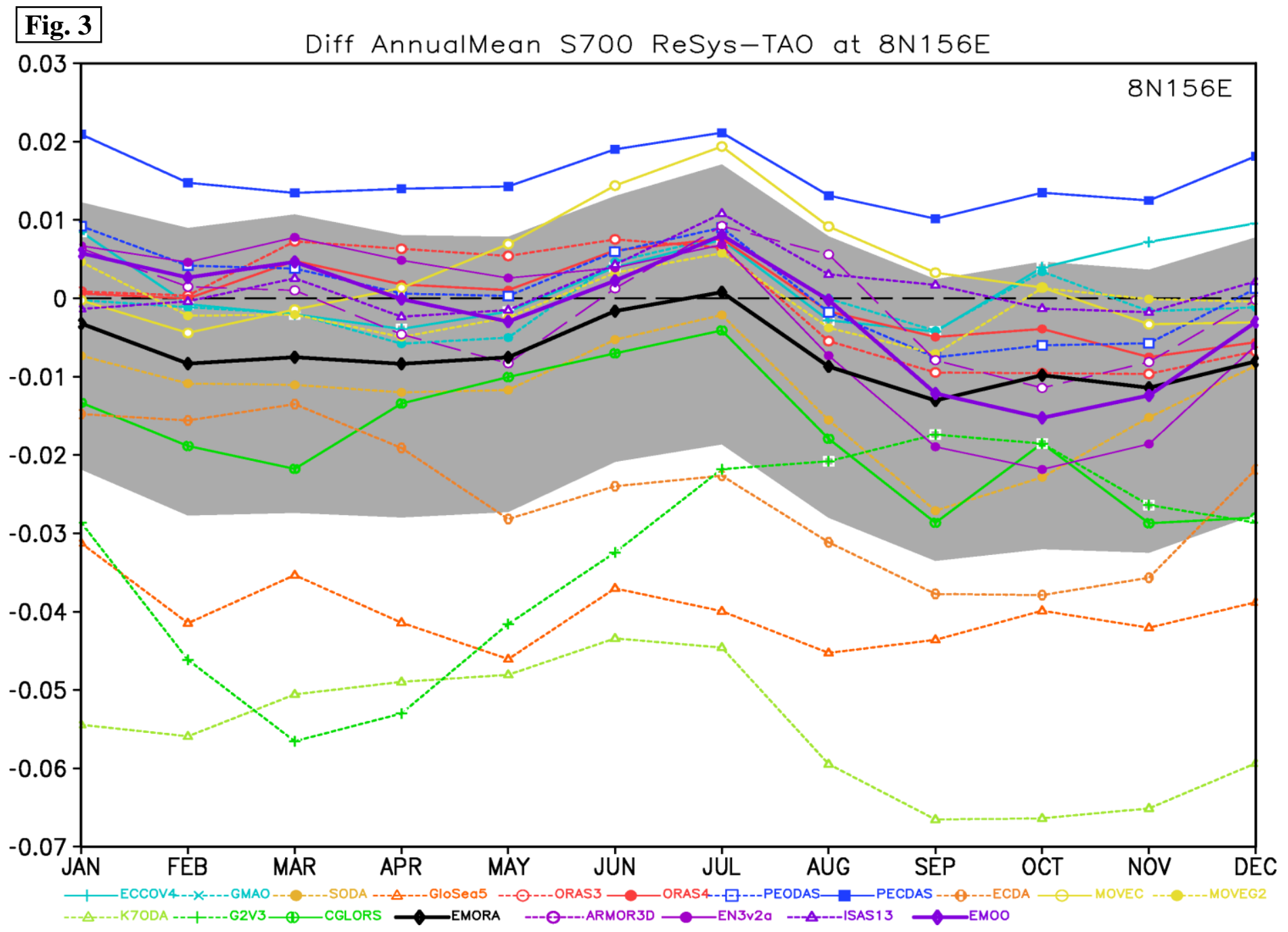

Fig. 3: Differences of the seasonal cycle (i.e. monthly climatology for the period 1999-2010) S700 between all products and the TAO/TRITON data at $8^{\circ} \mathrm{N} 156^{\circ} \mathrm{E}$. The definition of shaded band (i.e. $U C R_{E M O R A}^{S C}$ ) can be referred to the Eq. (A4). The unit of ordinate is $p s u$. 


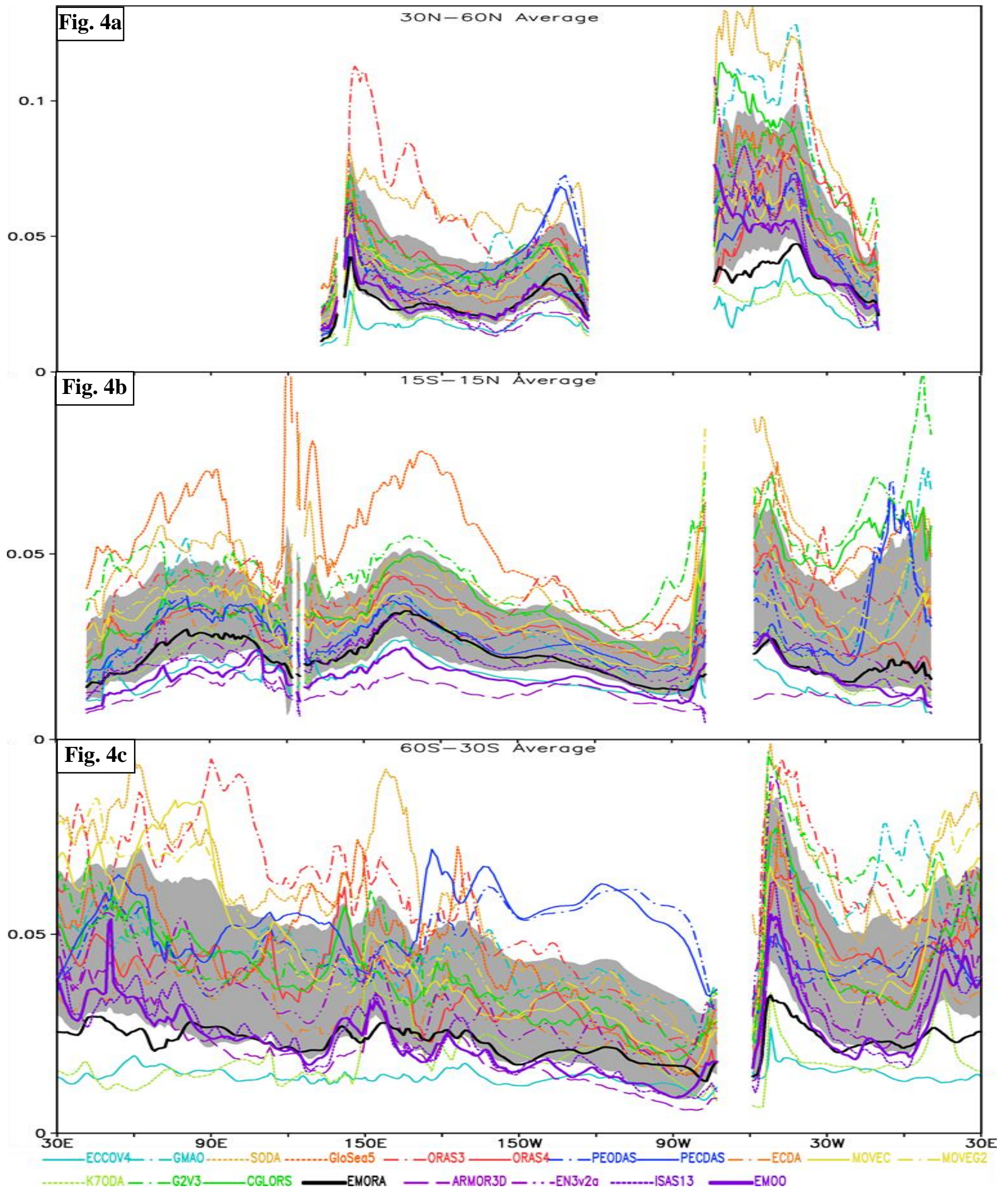

Fig. 4: (a) Zonal distribution of meridionally-averaged (over $30^{\circ} \mathrm{N}-60^{\circ} \mathrm{N}$ ) temporal standard deviation of $\mathrm{S} 700$ anomalies (i.e. $S T D_{n}^{A}$ ) from individual products for the period 1993-2010. The definition of shaded band (i.e. $U C R_{E M O R A}^{S T D}$ ) can be referred to the Eq. (A4). (b) Same as in (a), except for except for meridionally-averaged over $15^{\circ} \mathrm{S}-15^{\circ} \mathrm{N}$. (c) Same as in (a), except for meridionally-averaged over $60^{\circ} \mathrm{S}-30^{\circ} \mathrm{S}$. The unit of ordinate is $p s u$. 

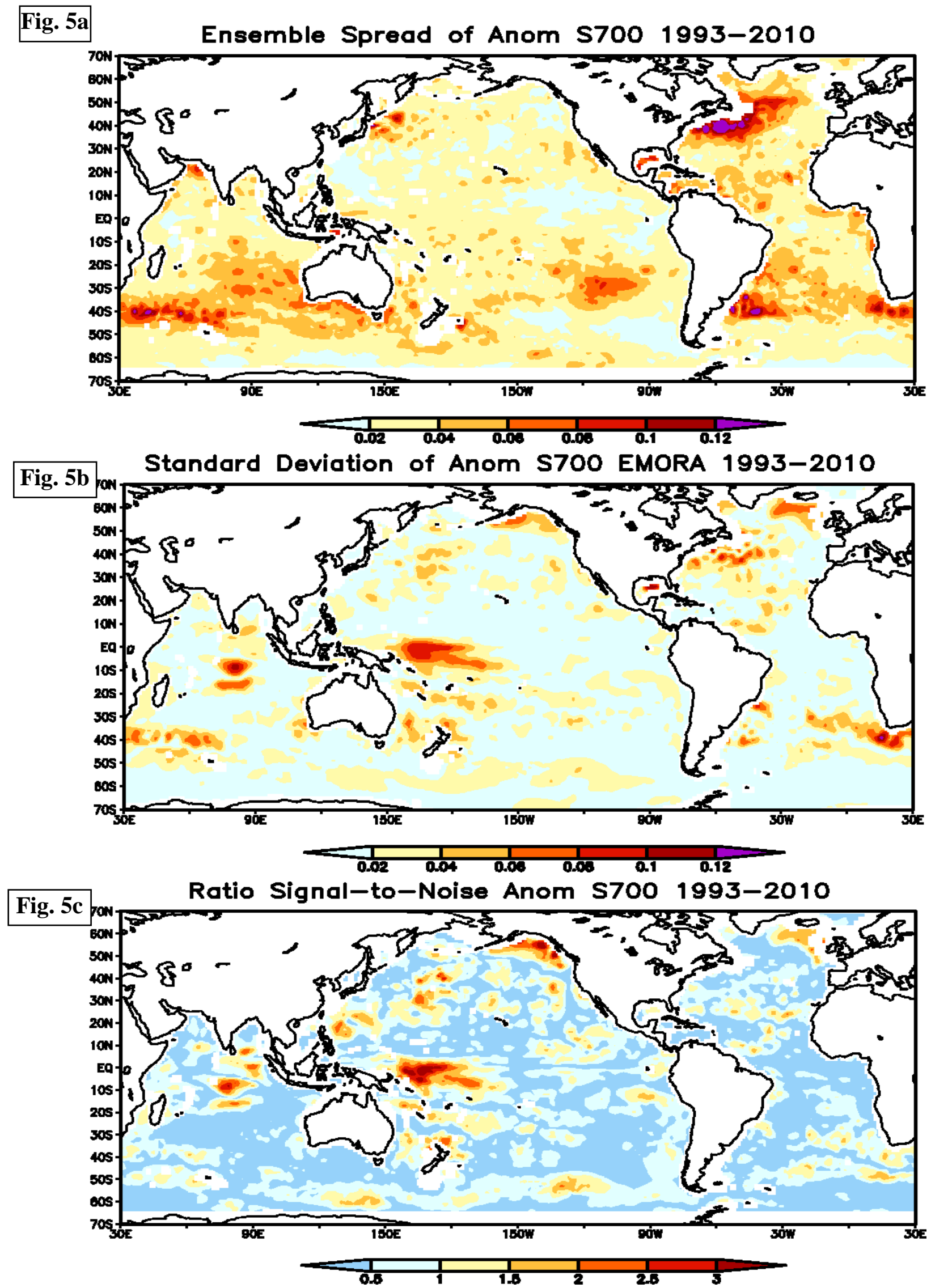

Fig. 5: (a) Distribution of ensemble spread of $S 700$ anomalies (i.e. $S P D_{E M O R A}^{A}$ ) from 14 ORAs about the corresponding EMORA for the period 1993-2010. (b) The temporal standard deviation of S700 anomalies from EMORA (i.e. $S T D_{\text {EMORA }}^{A}$ ) for the period 1993-2010. The unit of colour bar in (a)-(b) is psu. (c) The distribution of the estimated Signal-to-Noise Ratio $(S N R)$ of S700 anomalies from 14 ORAs for the period 1993-2010. 

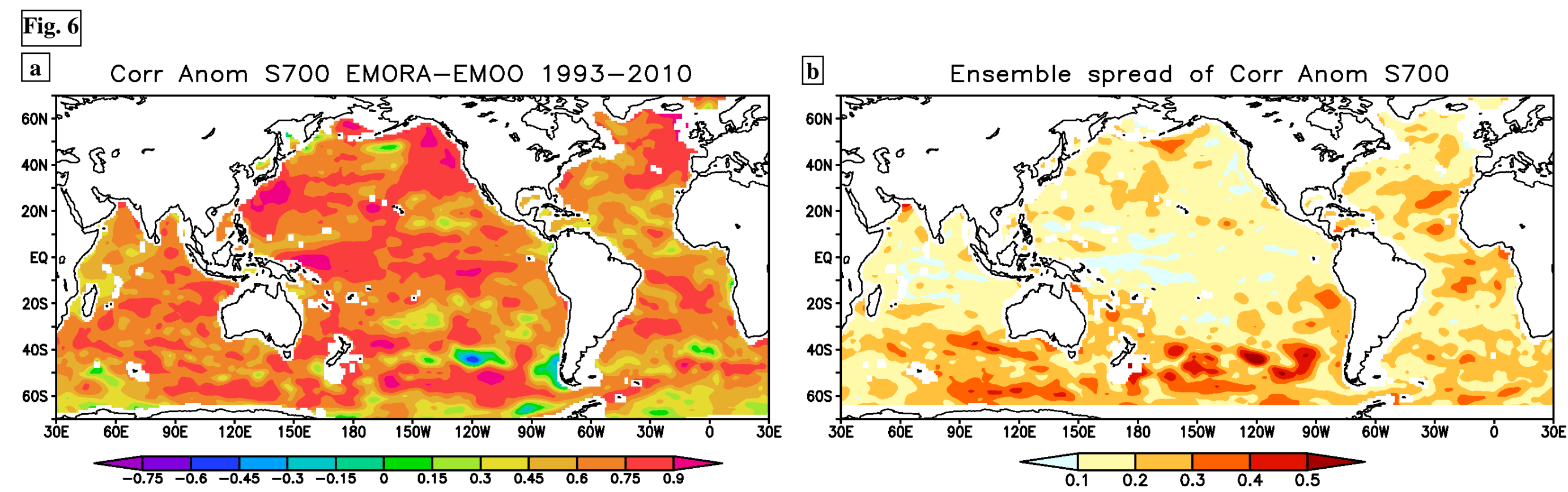

Fig. 6: (a) Temporal correlation coefficients of $\mathrm{S} 700$ anomalies between EMORA and EMOO for the period 1993-2010. (b) Ensemble spread (i.e. $S P D_{E M O R A}^{C O R}$ ) of correlation coefficients of S700 anomalies between individual ORAs and EMOO about their mean correlation coefficients. 


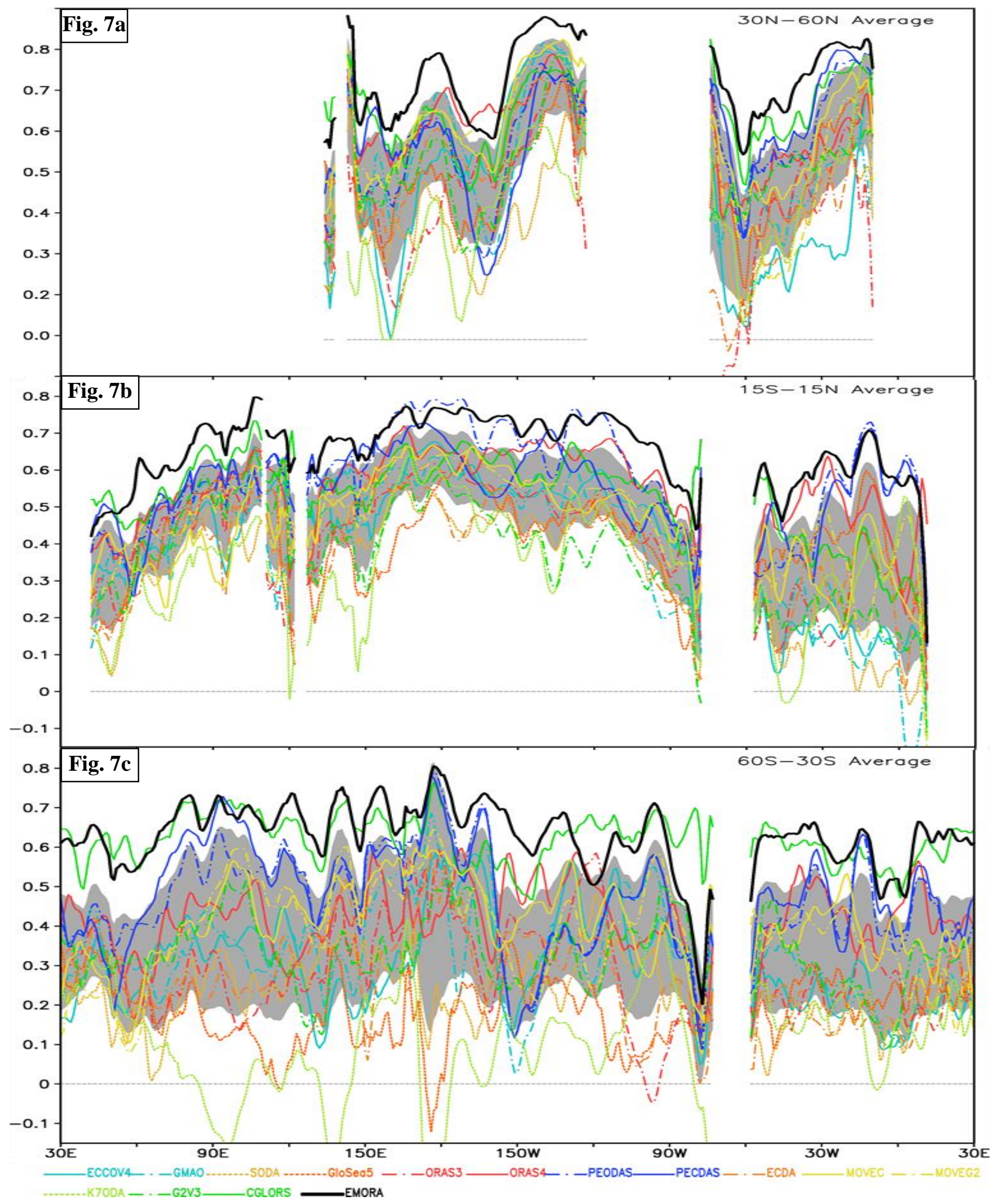

Fig. 7: (a) Zonal distribution of meridionally-averaged (over $30^{\circ} \mathrm{N}-60^{\circ} \mathrm{N}$ ) correlation coefficients of S700 anomalies between individual ORAs and EMOO for the period 1993-2010. The definition of shaded band (i.e. $U C R_{E M O R A}^{C O R}$ ) can be referred to the Eq. (A4). (b) Same as in (a), except for meridionally-averaged over $15^{\circ} \mathrm{S}-15^{\circ} \mathrm{N}$. (c) Same as in (a), except for meridionally-averaged over $60^{\circ} \mathrm{S}-30^{\circ} \mathrm{S}$. 


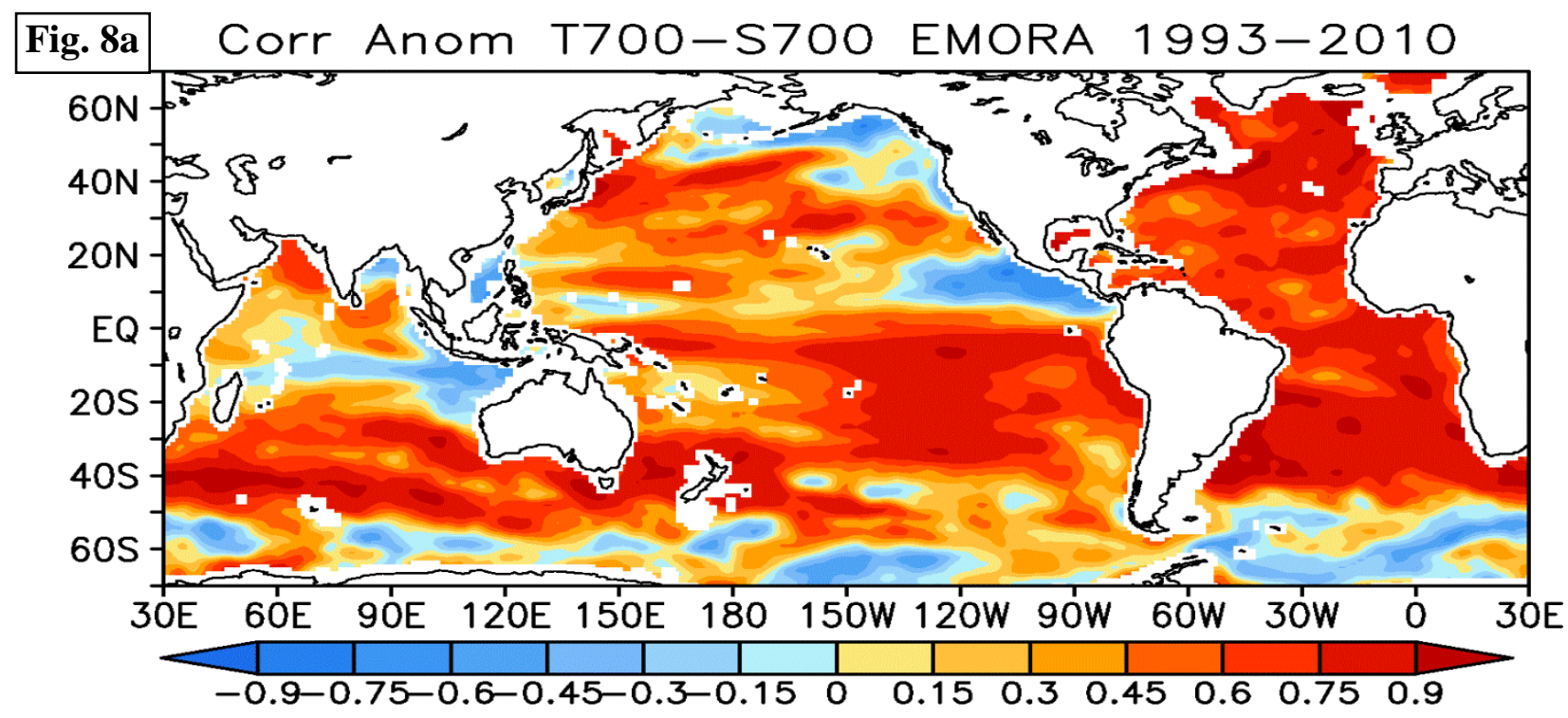

Fig. 8b Corr Anom T7OO-S700 EMOO 1993-2010

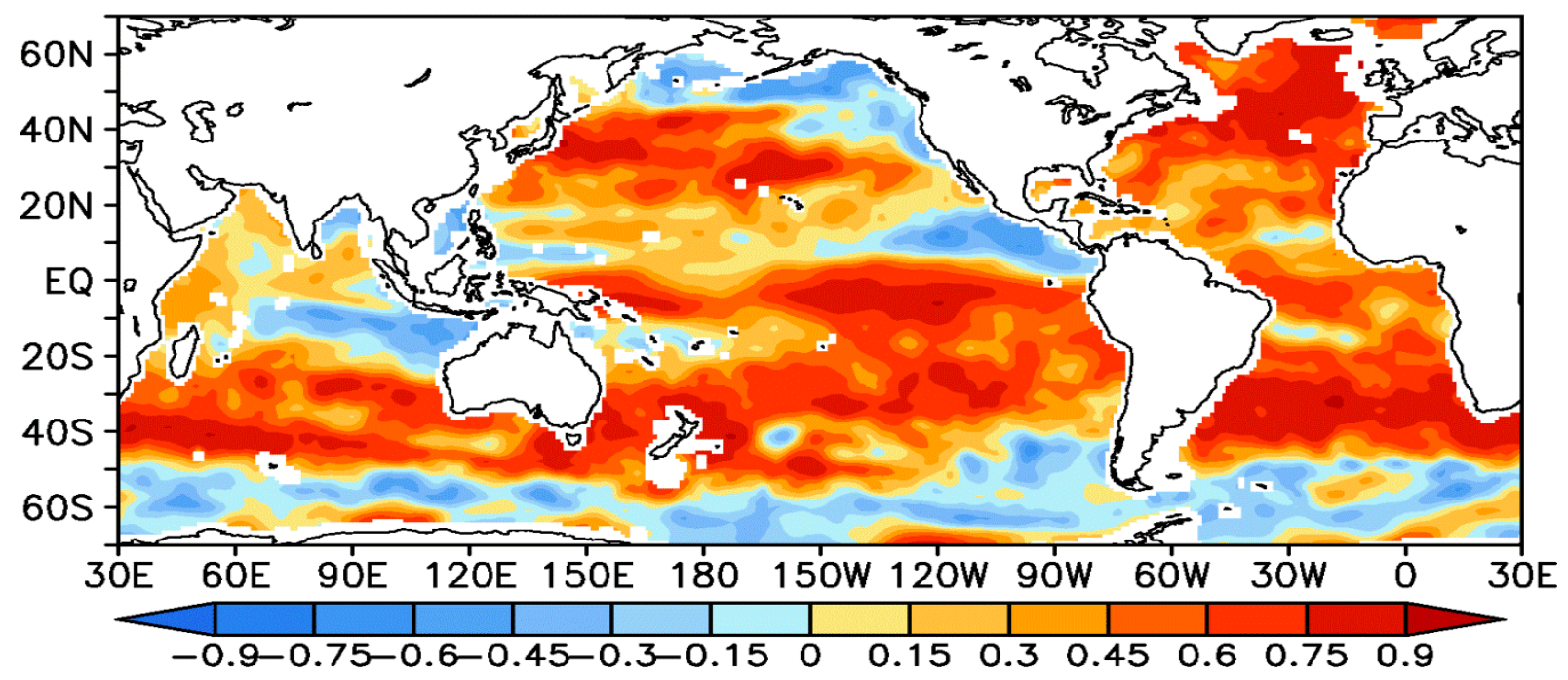

Fig. 8c Ensemble spread of Cor Anom T700-S700

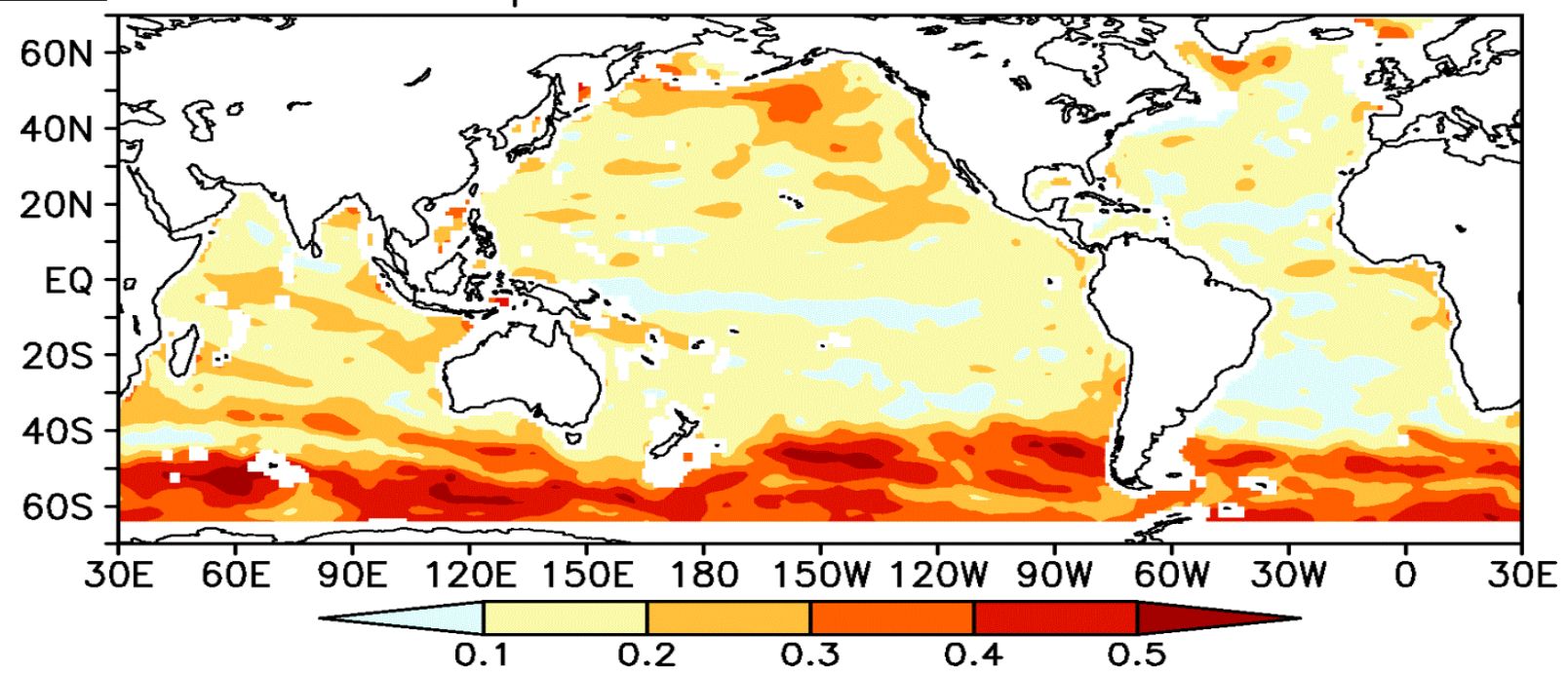

Fig. 8: (a) Temporal correlation coefficients between $S 700$ anomalies and $T 700$ anomalies from EMORA for the period 1993-2010. (b) Same as in (a), except for EMOO. (c) Ensemble spread (i.e. $S P D_{E M O R A}^{C O R}$ ) of T700-S700 anomalies correlation coefficients from individual ORAs about their mean correlation coefficients. 


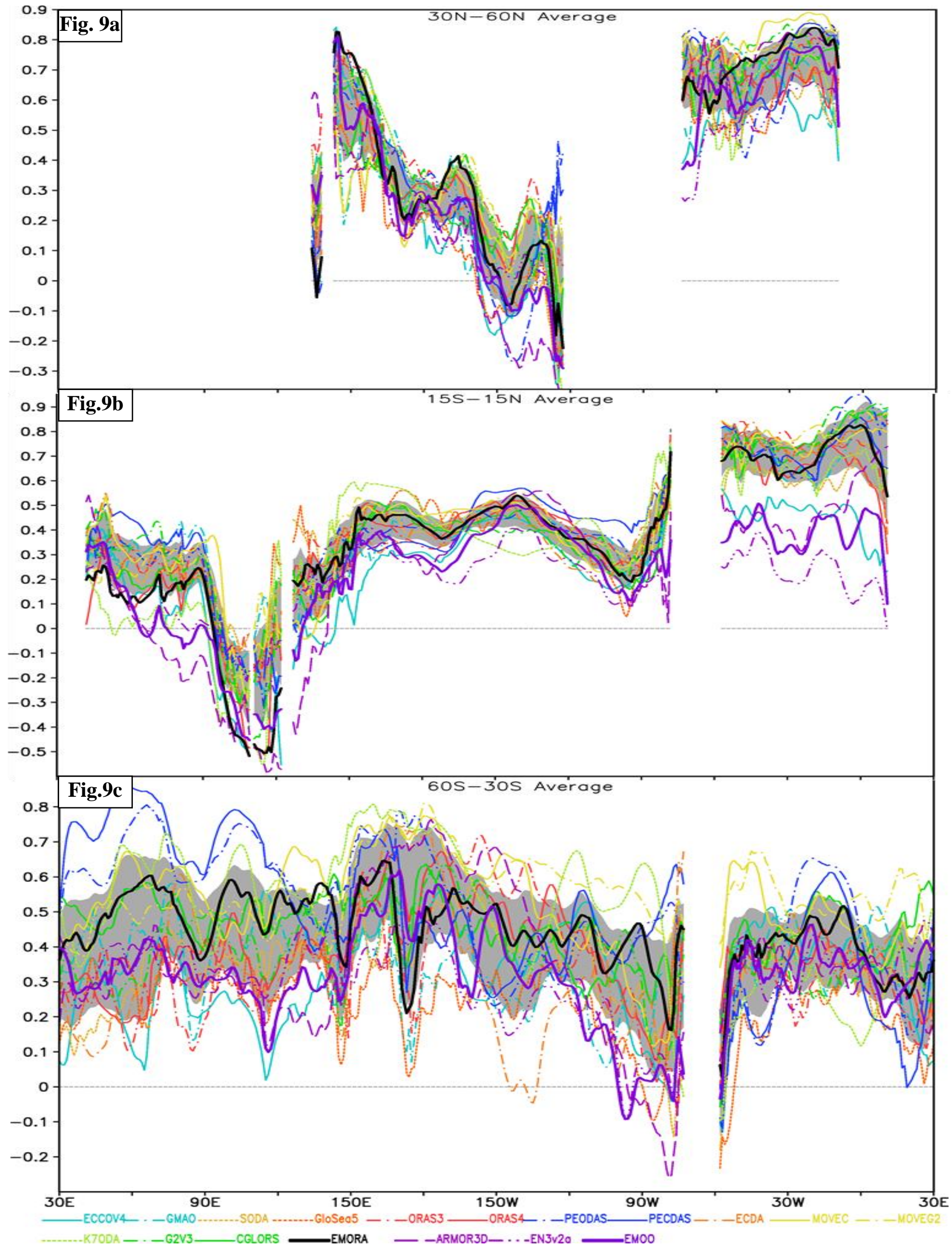

Fig. 9: Same as in Fig.7, except for correlation coefficients between the T700-S700 anomalies. 


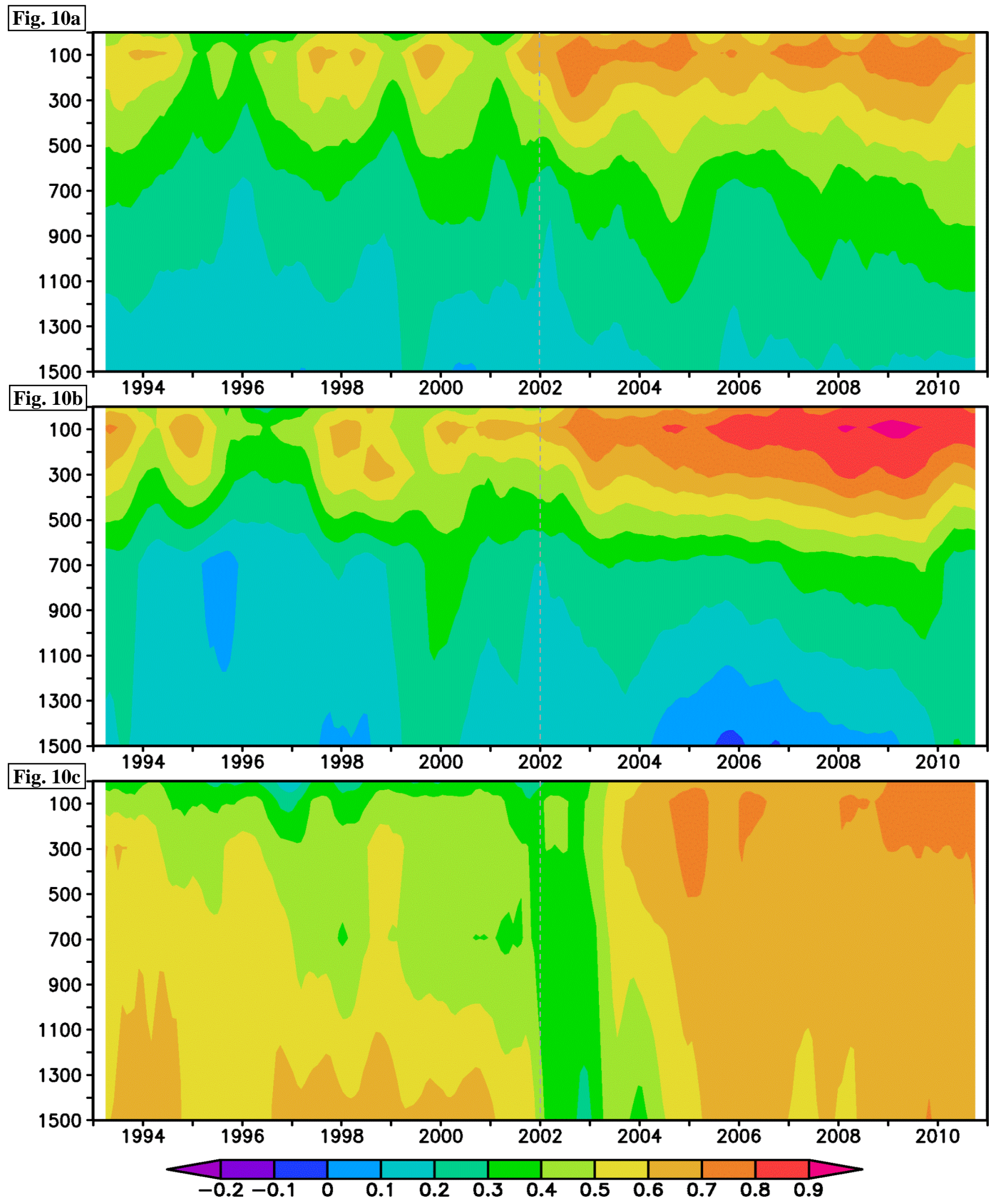

Fig. 10: (a) Centred pattern correlation coefficients (i.e. CPCOR; calculated over the band area $0-360^{\circ} \mathrm{E} ; 30^{\circ} \mathrm{N}-60^{\circ} \mathrm{N}$ ) of salt anomalies between EMORA and EMOO as a function of depth (0-1500m) and time (1993-2010. Prior to plotting a 7month running mean was applied on the computed correlation coefficients to remove the intra-seasonal variability. The ordinate has units meter (m). (b) Same as in (a), except for the band area $0-360^{\circ} \mathrm{E} ; 15^{\circ} \mathrm{S}-15^{\circ} \mathrm{N}$. (c) Same as in (a), except for the band area $0-360^{\circ} \mathrm{E} ; 60^{\circ} \mathrm{S}-30^{\circ} \mathrm{S}$. 


\section{Fig. 11}

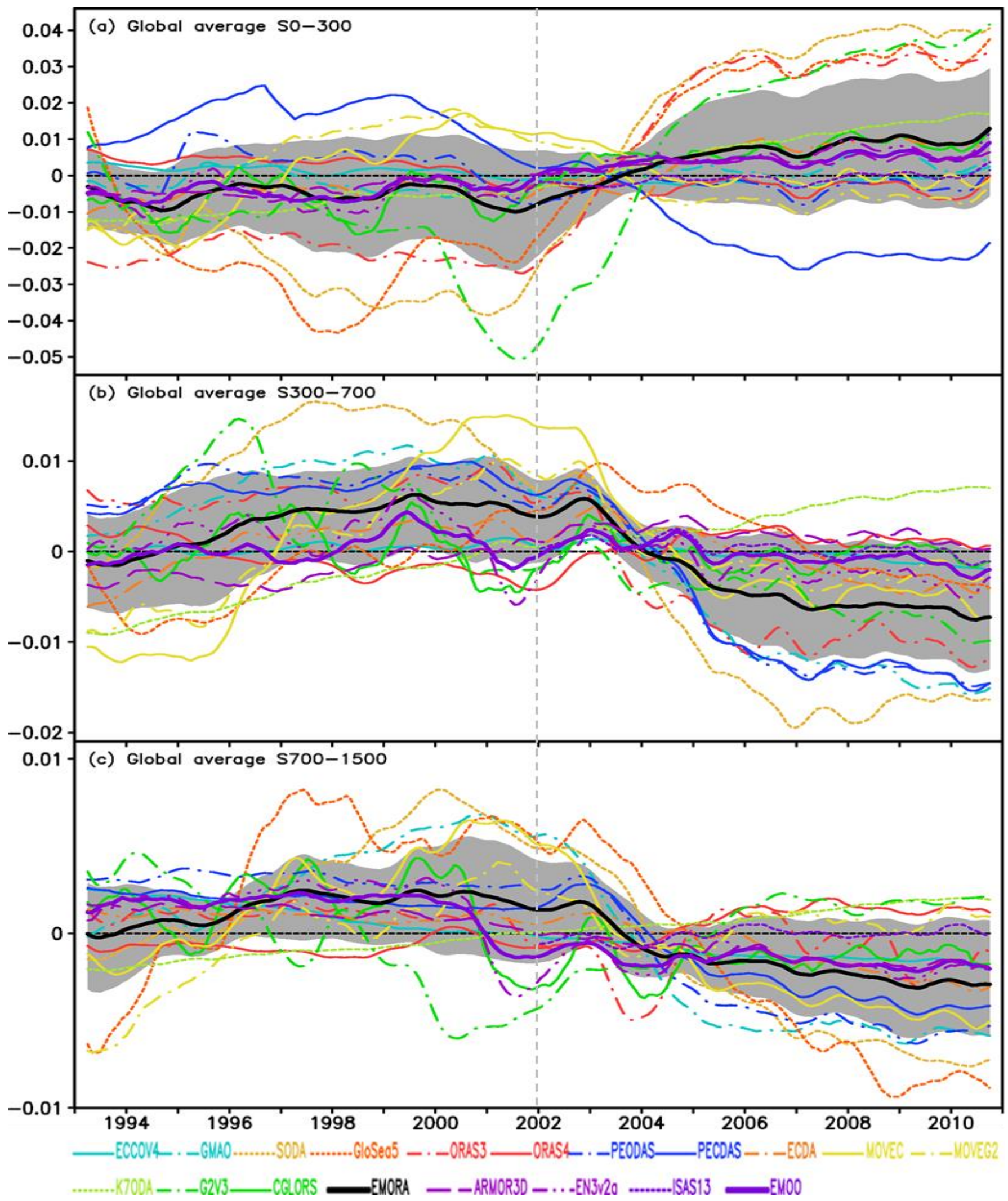

Fig.11: (a) Evolution of global averaged (over $0-360^{\circ} \mathrm{E} ; 60^{\circ} \mathrm{S}-60^{\circ} \mathrm{N}$ ) and depth-averaged (within 0-300m ocean layer) salinity anomalies from all products for the period 1993-2010. The definition of shaded band (i.e. $U C R_{E M O R A}^{A}$ ) can be referred to the Eq. (A5). The unit of ordinate is psu. (b) - (c) Same as in (a), except for depth-averaged salinity anomalies within 300-700 meters layer and 700-1500 meters layer, respectively. Prior to plotting a 7-month running mean was applied to remove the intra-seasonal variability. 